\title{
A Salt Inventory Management Strategy for Winter Maintenance
}

\author{
Frank W Ciarallo \\ Department of Biomedical, Industrial and Human Factors Engineering \\ Wright State University \\ Dayton, OH 45435, USA \\ E-mail: frank.ciarallo@wright.edu \\ Suman Niranjan \\ College of Business Administration \\ Savannah State University \\ Savannah, Georgia 31404, USA \\ E-mail: niranjans@savannahstate.edu (Corresponding Author) \\ Nick Brown \\ Systems Engineer \\ Evanhoe \& Associates, Inc \\ Dayton, Ohio, USA \\ E-mail: brown.nick.andrew@gmail.com
}

\begin{abstract}
Expenditures for winter maintenance materials total nearly \$20 million annually in a mid-western USA state. During an average winter the State Department of Transportation (DOT) uses approximately 666,000 tons of rock salt and has the capacity to store roughly 617,000 tons of material at various locations. Each year, each county in this Mid-western state establishes a contract through DOT with a salt vendor before the winter season and that vendor supplies all garages in the county for the entire season. In order to develop a systematic salt inventory management strategy that achieves the statewide goals for safety, ordering guidelines for each county that specify when to order and how much to order based on an $(R, S)$-inventory guideline is developed. These guidelines take into account the history of usage and deliveries in a county, as well as the monthly variation in usage. The inventory guidelines developed for the different areas of the state are based on a weather regression model for the major cities/counties in the state relating usage to weather. The guidelines were tested and refined using a computer simulation methodology. The resulting guidelines are compared to the state's current DOT guidelines for inventory, as well as compared to the county storage capacities to develop recommendations.
\end{abstract}

Keywords: application, salt inventory, winter maintenance

\section{INTRODUCTION}

Use of winter maintenance materials is critical to maintaining safe economic and social activity in the State during the winter season. Each year, snow and ice storms create situations filled with danger to the public and potentially enormous economic cost. The rate of traffic accidents has been observed to increase by a factor of 100 during a winter storm (Knapp et al., 2000). It is well known that during winter storms, the use of salt and other treatments has a large impact on safety. For example, one study found that the rate of accidents decreases by a factor of 4.5 times in the two hours after roads have been treated following a snowfall, and that the rate for injury accidents decreases by a factor of seven times (Hanbali and Kuemmel, 1992). The economic impacts of prolonged road closures or delays to the clearing of roads are significant. It has been estimated that the effect per day of a snowfall "shut-down" in this Mid-western state has a total economic impact of \$281 million (Arnsler, 2004).

\subsection{Background}

County trucks that each hold 10-12 tons of material spread salt and brine solutions on roads before, during, and after a storm to manage ice and snow build up. It is crucial that the storage bins at the county garages do not run out of salt during the winter season.

The salt supply chain for winter maintenance for the State is summarized in Figure 1. The salt supply chain begins in the mines, from which salt is distributed with minimal processing. The salt leaves the mine (both vendor-owned and third party mines) and is deposited at a regional vendor stockpile. The salt is then transferred from the regional vendor-owned stockpile locations to State vendor-owned stockpiles in the mid-western USA by way of rail or barge. 
From the State stockpile the salt is moved by contracted carriers by over-the-road trucks to State-owned county garages. This process of stocking the salt bins for the winter season begins in the summer months and continues until a specified volume is reached in the county garages, usually before the start of winter weather. During the winter season salt is used and replenishments are ordered by the county.

Each year, each county establishes a contract through DOT with a salt vendor before the winter season and that vendor supplies all garages in the county for the entire season. The supplier selects one of its stockpile locations that will supply the contracted county for the term of the contract. Only one vendor supplies a county, but many counties can be supplied by one vendor.

In this work, in order to develop a systematic salt inventory management strategy that achieves the statewide goals for safety, ordering guidelines for each county that specify when to order and how much to order based on an $(R$, $S)$-inventory guideline were developed for the State. These guidelines take into account the history of usage and deliveries in a county. This guideline is valuable because it more closely matches the county inventories to the actual demand, which results in more efficient snow removal operations.

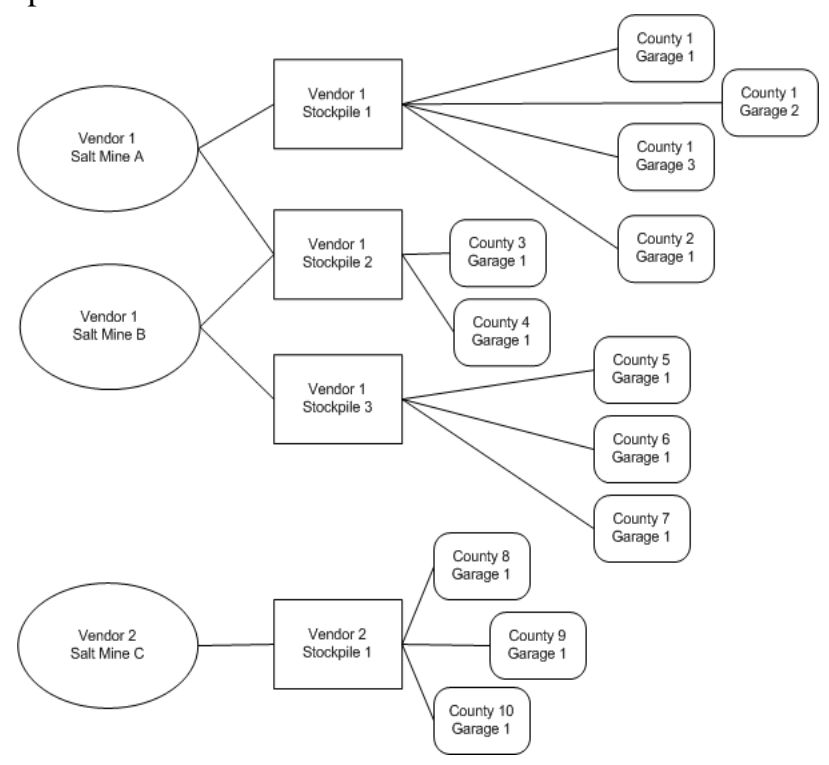

Figure 1 The Salt Supply Chain

In the academic literature, there is a long history of studying inventory and materials management. These models describe the structure of ordering decisions in inventory management situations. Management of inventory is a critical decision in the effective operations of supply chains in support of customers. The literature review section summarizes some recent advances in these types of models.

A fundamental insight of inventory management is that in determining $r$ (the re-order point) one must consider the statistical variation of demand during the delivery lead time. Simultaneous computation of $Q$ and $r$ to minimize the average cost over time is the result of this approach. The $(Q, r)$-type guideline assumes that orders to replenish inventory can be placed at any time. The "newsvendor" type models are a related class that assumes that orders can only be placed on a periodic basis (for example, once per week). Similar "orderquantity" and "safety stock" results are available for this type of model. In this context, the guidelines are called $(S, s)$ guidelines. For each of these ordering approaches, a description of the range of possible demands over some base time period is critical to developing the order quantities and re-order points. These descriptions are statistical in nature, rather than precise forecasts, and should be based on historical information.

\subsection{The Problem}

Over the decade preceding this study, the state nearly ran out of salt in two places, and few winters in the state were very severe compared to the normal winter. Several salt storage locations in the county had excessive salt inventory at the end of the season. The primary objective of this study was to develop new inventory guidelines that minimize the probability of a stock-out situation, and at the same time help minimize the amount of salt held in inventory both during and at the end of the season. This project developed an $(R, S)$ inventory guideline for use in every county. The guideline systematically identifies whether a county manager should order salt each week and how much should be ordered. Using a weather regression model, a demand model was developed to more accurately support the inventory guideline parameters that balance shortage risk and inventory cost. To assess the effectiveness of the guidelines a simulation of salt deliveries and usage was developed that closely resembles the actual system at an appropriate level of detail. All data pertaining to salt usage, received, and beginning amounts were from the state DOT. The development of the weather regression model used data from the National Oceanic Atmospheric Administration (NOAA), collected by the National Climatic Data Center.

The rest of this paper is organized as follows: Section 2 presents a review of literature in the area of inventory guidelines, supply chain management and their application to bulk commodities. Section 3 gives an overview of the policy structure and the approach to develop all the parameters that support it. Section 4 presents the regression model relating salt used to weather variables. This chapter also details the regression models developed for the 7 major weather zones in the state. Section 5 presents the $(R, S)$-inventory guidelines developed using the weather model for each weather zone. Section 6 presents results and refinement of the inventory guidelines through simulation tested against actual usage from the state DOT databases. Section 7 presents conclusions and some suggestions for implementation and future work.

\section{LITERATURE REVIEW}

The research of existing literature is focused in two background areas of knowledge that supported our findings: i) Literature on inventory and supply chain management, ii) Knowledge from the winter maintenance professional groups, DOT's and materials suppliers. 


\subsection{Inventory and Supply Management}

There has been very limited published material specifically focused on the use of inventory management strategies for winter maintenance materials. The general principles from this section are applicable across the universe of inventory management problems.

As described earlier, inventory and material management models describe the structure of ordering decisions in inventory management situations. The standard models (Nahmias, 2005) include: i) "Economic Order Quantity" (EOQ) models and ii) Models with uncertainty in demand: which leads to the use of $(Q, r)$ guidelines. In a $(Q, r)$ guideline, orders are placed when the inventory level drops to the level $r$. The work by Roelants and Muyldermans (2002) is closely related to the work on this project. It describes salt inventory management guidelines based on the $(Q, r)$ model developed in Belgium that focus on matching salt inventories to actual demand during the winter months.

Many recent papers have explored inventory control policies that are matched to the requirements of a given inventory management scenario. Tempelmeier and Fischer (2010) develop a $(r, s, q)$ inventory policy for a single-item, periodic review setting which is a modified version of the continuous review $(s, q)$ policy, where $s$ is the reorder point, $q$ is the reorder quantity and inventory is reviewed every $r$ periods. A major contribution of this work is an estimate of the customer waiting time distribution while using the $(r, s, q)$ inventory policy. In a later paper Tempelmeier (2013) develops a multi-level inventory optimization model that uses a discrete-time reorder point-order quantity policy for the central warehouses, and a base-stock policy for distribution centers. The results focus on optimized values of decision variables at the factory, warehouse and distribution center. Qin and Kar (2013) derive an optimal order quantity that provides maximum profit for an uncertain demand expressed linguistically. Gao et al. (2013) expands on this model by introducing an initial stock as well as set-up cost. The $(s, S)$ policy is shown to be an optimal inventory policy for a singleperiod problem.

Hajiaghaei-Keshteli et al. (2010) considers a threeechelon serial inventory system with two warehouses and one retailer that uses a continuous review $(R, Q)$ inventory policy at the retailer. This work develops a new ordering policy that emphasizes the benefits of sharing information between echelons leading to an exact model of cost. Ma et al. (2014) considers a multi-echelon supply chain with manufacturer, upstream suppliers, downstream distributors, and demand from customers. The distributors use a $(t, R, S)$ policy and the manufacturer uses a $(R, Q)$ policy. This work uses a multiobjective time and cost optimization that considers total inventory turnover time and inventory cost. Katehakis and Smit (2012) studies the continuous review $(Q, r)$ inventory policy and shows that the policy is optimal for quantity discounts. Lee and Behnezhad (2015) further shows that an order-up-to policy is optimal under a general demand distribution for the same incremental quantity discount model for a multi-period and infinite horizon setting.
During heavy demand periods, supply can become uncertain because of difficulties in deliveries. Roads may be difficult to travel for delivery vehicles, and rivers may be frozen limiting barge traffic. In addition, suppliers may be hard pressed to keep up with demand when the entire region has been hit by a prolonged sequence of winter storms. Consideration of supply and demand uncertainty issues when determining safety stock will be critical to a successful inventory management strategy. Ciarallo et al. (1994) develops one of the fundamental models for managing inventory with supply and demand uncertainty. Recent developments in the literature include the following: Gumus et al. (2012) studies the value of diversifying supply to more than one supplier and the use of price and quantity guarantees to mitigate the effect of an unreliable supplier. He and Zhao (2012) proposes contracts with a returns policy for a multiechelon supply chain that creates a win-win situation for suppliers and retailers. Chaturvedi and Martinez-de-Albéniz (2011) studies auction mechanisms for allocating supplier capacity to buyers with different levels of public information about supplier reliability. Iida (2015) identifies optimal statedependent base-stock policies and heuristic policies to directly utilize lead time information and demand forecast information in inventory control decisions where lead time is uncertain. Parlar et al. (1995) studies optimal policies in a Markovian model of supply for a periodic review setting with setup costs that uses information about supply availability in the previous period.

In recent years, the relationship between buyers and suppliers has received considerable attention, due to the globalization of markets, corporate restructuring, and increased focus on costs, quality, flexibility, technology, and an expanded role for procurement. Previously, purchasing was considered as a clerical function, where the relationship between buyers and suppliers was adversarial, but now many organizations have employed a more collaborative approach to procurement planning (McHugh et al., 2003). The state DOT contracting process solicits and establishes a contract for each county each year that results in a single supplier for each county. The level of inventories at the county level is critical since a secondary source of supply may be difficult or impossible to obtain if the counties contracted supplier is not able to deliver reliably. This single source model also emphasizes the need for a collaborative relationship between the state DOT and the suppliers to make continual improvements in trust, communication, technical capabilities, supplier supervision and cooperation. Keramydas et al. (2011) studies the supplier assessment, selection and evaluation problem and describes a five-phase framework for supplier selection based on a goal programming approach. Hayashi et al. (2009) describes the use of a strategic map to coordinate decision making from planning through production through sales in modern supply chains using a collaborative approach.

\subsection{Winter Maintenance Industry}

Industry groups such as the Salt Institute (www.saltinstitute.org) are a significant source of background 
information. There is a detailed science to the materials used and their mode of application in order to ensure that roads are clear. This includes pre-treatment of roads prior to a storm, as well as treatment after a snowfall. For example, the extent to which materials are used for pre-treatment will impact the types of storage used. Salt is typically used at the county garages to create brine solution that is used for pre-treatment. The amount of time in storage and the type of storage can have a large impact on how easily the materials can be spread. For example, salt that has been exposed to the weather and saturated with water can be much more difficult to spread and must be spread at a higher rate to ensure coverage when it is wet. Also, salt stockpiles can be depleted by exposure to rain.

\section{DEVELOPMENT OF THE INVENTORY CONTROL MODEL}

\subsection{Overview of the Guideline Structure}

An $(R, S)$ - inventory guideline is a combination of the $(Q, r)$ and $(s, S)$ inventory models. The $(R, S)$-model was investigated in a paper by Roelants and Muyldermans (2002) for management of salt inventories. It utilizes the continuous review reorder point and the target or order up to level of the periodic review system. The purpose of the model is to determine when to order and how much material should be ordered. This is different than the $(Q, r)$ model which allows orders to be placed at any time, but always orders the same amount. The periodic review $(s, S)$ inventory guideline places orders at pre-determined times, with varying order amounts. In a $(R, S)$-inventory guideline a reorder point $(R)$ and a stock/target level $(S)$ are established to support the goals of the organization. To protect from shortages during the lead times a safety stock (SS) is also included in the reorder point $(R)$.

\subsection{The (R, S)-Inventory Guideline Weather Severity Index Application}

The service level suggested by Roelants and Muyldermans (2002) is set to a very high $99.8 \%$. In this paper the guideline is developed by utilizing a multi-linear regression, where past weather variables are matched up with past salt usage for corresponding days to develop a demand model. These $(R, S)$-inventory guideline models contrast with the typical practice of stocking the salt domes to capacity during the summer months and only reduce inventories sometimes towards the end of the winter season. Inventories left over at the end of the winter season are held and maintained until the following winter. This incurs costs and ties up capital. For example costs are incurred to prevent the deterioration of salt.

A regression model was developed with the salt usage as the dependent variable and the weather event data as the independent variables. Using the statistics of the model output the $(R, S)$-inventory guideline parameters are calculated. The reorder point is calculated using equation (1).

$R=s S+\mu_{L T}$
The mean demand during the lead time $\left(\mu_{L T}\right)$ is the mean of the predictions. The safety stock (ss) is computed from the standard deviation of the predicted demand during the lead time, $\sigma_{L T}$, multiplied by the safety factor, $k$. For a Normal model of the variation in demand the value of $k$ is 2.88 , based on a $99.8 \%$ service level.

ss $=k \sigma_{L T}$

$S=R+E$ [weekly demand $]$

This approach to setting target levels assumes that orders are placed approximately once per week on average. This allows the target stock level to be based on average weekly usage, rather than requiring an estimate of ordering and holding costs, as in the EOQ-type models. Because these cost parameters are difficult to estimate, this is a preferred method of implementing the ordering guidelines in practice.

In this project the $\mu_{L T}$ and $\sigma_{L T}$ values were computed separately for each month of the winter season. For example, there is a different $\mu_{L T}$ and $\sigma_{L T}$ for each of November, December, January, February, and March. Because of this, each month has a different $R$ and $S$ value. A more detailed model could be developed that has $R$ and $S$ values that change weekly. The Roelants paper suggests a second method that utilizes historical salt usage directly to estimate values for the parameters $\mu_{L T}$ and $\sigma_{L T}$ for each month, rather than using the output of the multi-linear regression weather model. In this alternate approach, the $(R, S)$-guideline values are calculated directly from the historical usage using the same procedure based on equations (1) - (3). The findings of the Roelants paper is that the first model using multi-linear regression with weather events is more accurate than using historical data, but requires more data and time. The second model using the historical data is less accurate, but is easier to use and requires less data. Overall the second method tends to result in guidelines that wait a small amount of time longer to reorder.

In an effort to determine relationships between winter activities and different weather conditions, the State of Indiana in U.S.A developed a weather severity index to estimate total costs per mile. McCullouch et al. (2004) reviews many other weather severity indices developed by Wisconsin DOT, Washington State DOT, Hulme, and Strategic Highway Research Program Index (SHRP). McCullouch et al. (2004) defines useful weather variables and found that the most influential were the number of days of frost, freezing rain, drifting of snow, and snow events. After developing a regression model with these four factors they added other factors such as average temperature, storm duration, and snow depth. The result was that as more weather factors were added to the regression, the closer the predictions got to the actual costs per lane mile. It was also found that due to different climatic zones of Indiana that one regression model for the entire state was not appropriate. The state was thus broken up into four regions and data for the major city in each of the zones was used in the regression model.

The following sections detail the models and results used to develop guidelines for each county in the State, with an integration of the philosophical and technical approaches we found while investigating the related literature. 


\section{THE WEATHER REGRESSION MODEL}

In this section we identify the weather variables which are significant in determining salt usage for the regions of the State. The significant variables for each city/county are determined by comparing the accuracy of the regression models that include different combinations of weather variables. The results are a weather regression model that supports predicted salt usage for the most populated counties based on the observed weather. These regression models will drive the monthly demand model used to calculate the $(R, S)$ inventory guideline parameters.

\subsection{Defining the Significant Weather Variables}

A weather regression model for each of the Counties for the State was developed based on weather variables imported from weather history files from the National Climatic Data Center (NCDC) and the National Oceanic and Atmospheric Administration (NOAA) web sites.

A variety of different weather variable combinations were considered, in order to develop the most accurate, but reasonably compact, weather regression model. The weather variables were accumulated by week for the range of years over which the study was conducted. These weekly weather variables were matched up with the corresponding weekly salt usage (by county) from the State's DOT databases. A linear regression model with salt usage as the dependent variable and the weather variables as the independent variables was fit for each month, using several years of data. These estimates were used to find predicted values of salt usage for each week. After this is done for all of the historical data, the statistics of the predicted usage values are used for the next part of the model: computing reorder points, safety stocks, and target stock levels. Figure 2 diagrams the process of the formulation of the $(R, S)$ - inventory guideline.

Roelants and Muyldermans (2002) found that an $(R, S)$ inventory guideline performs better when utilizing regression output to calculate the mean and variance of usage rather than simply calculating the $(R, S)$ parameters directly from the historical data. Since the suppliers in the state are allowed one week ( 7 days) in their contracts to make the delivery we consider the lead time as one week. The calculations use weeks as the base time unit instead of months, which differs from Roelants and Muyldermans (2002). Each year's data begins on November 4 and ends either March $29^{\text {th }}$ or $30^{\text {th }}$ depending on whether that year is a leap year. This time period constitutes a total of 21 weeks per year for each of the 7 years of data from November 1998 - March 2005. The nonwinter months from April - October are not included in the model. A week is considered to be part of the month in which the week begins. For the model for a county the weather variables are based on data from the major city in that county and the supporting salt usage data is for the entire county.
One very important weather factor is the amount of snowfall (in.). In the model, one must decide whether "trace" snowfall on a day is considered a "snow event". In the weather data recorded by NOAA, trace amounts of snow are recorded as .001 (in.). The amount of snowfall variable will either include trace amounts of snowfall ( $>0 \mathrm{in}$.) or include only snowfall amounts greater then a trace ( $>.001$ in.). In the same way that snowfall amounts are recorded, the number of days of snowfall in a week is accumulated. Thus there are two options: whether to include a trace snowfall amount as a day of snow or only include measurable snowfall above a trace in the model.

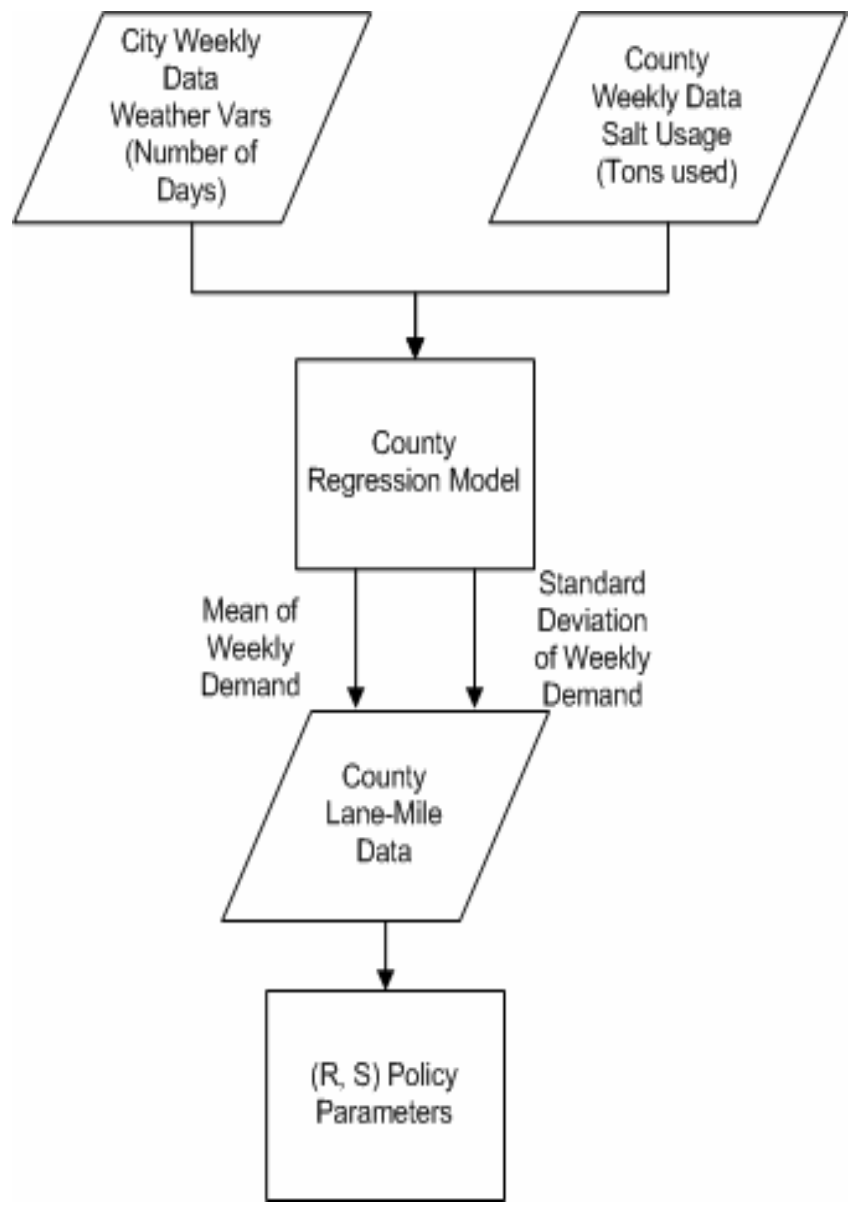

Figure $2(R, S)$ Inventory Guideline Development Process

Another weather variable that depends on the treatment of trace amounts of snow is the snow cover or depth on the ground recorded by the weather station at 7 a.m. Two other weather variables considered for the weather regression model are the number of days of freezing rain and blowing snow in the week. These are directly available from the NOAA data. The final weather variables that were considered for the regression model were minimum, maximum, and average temperatures bounded by a predefined temperature. These variables are optimally bounded by whether they are less than 30 degrees Fahrenheit $\left(<30^{\circ}\right)$ or less than 32 degrees $\left(<32^{\circ}\right)$. 
Table 1 Defined Weather Variables

\begin{tabular}{|lll|}
\hline Events & Symbols & Definitions \\
\hline Snow & Sn & Amount of Snowfall $>0$ in. \\
& Amount of Snowfall $>0.001$ in. \\
\hline Days of Snow & DSn & Number of days of Snowfall $>0$ in. \\
& Number of days of Snowfall $>0.001$ in. \\
\hline Freezing Rain & FzR & Number of days with Freezing Rain/Freezing Drizzle \\
\hline Blowing Snow & BSn & Number of days with Blowing Snow \\
\hline Snow Cover & SnC & Number of days of ground snow cover $>0$ in. \\
& & Number of days of ground snow cover $>.001$ in. \\
\hline Minimum Temperature & MinT & Number of days with minimum temperature $<30^{\circ}$ \\
& & Number of days with minimum temperature $<32^{\circ}$ \\
\hline Maximum Temperature & MaxT & Number of days with maximum temperature $<30^{\circ}$ \\
& & Number of days with maximum temperature $<32^{\circ}$ \\
\hline Average Temperature & AveT & Number of days with average temperature $<30^{\circ}$ \\
& & Number of days with average temperature $<32^{\circ}$ \\
\hline
\end{tabular}

\subsection{Comparisons for Finding the Combination of Weather Variables}

The process of finding the best model was accomplished in the JMP 5.1 software, considering the $R^{2}$, adjusted $R^{2}$, and also the mean square error. Comparisons of the different models were made in a systematic exploration of different sets of variables. Each of the comparisons for a month is only used with one set of temperature and snowfall variances. For example the maximum, minimum, and average temperature considered were "less than $30^{\circ}$ " or "less than $32^{\circ}$ " and all variations of snowfall are varied by "greater than 0 in." or "greater than a trace (.001 inches)".

Each of the potential regression models was investigated for the 8 major cities and their corresponding counties. This process determined a unique regression model for each of the months of November, December, January, February, and March. A total of eight cities and their corresponding counties were included in the study (unable to include the names of the cities and counties due to restriction from the state DOT). Cities in similar weather zones were also analyzed to see if a weather based regression model for salt usage for one city can be utilized for another city. The only areas that were studied to find a common weather regression model were three cities in the north of the state. These areas are in such close proximity that a common model may be possible.

In the detailed description below, only the results for the city of Cloveland (hypothetical city) are described in detail to document the development of the regression model. The same methodology was used for the other cities, but only the final results are provided for these other cities. After the development of the models for the 8 major counties, the models for three of these counties were tested in counties in the same region as the one for which they were originally developed. This was utilized to test if one weather regression model could be used for more than one county in the same region.

Figure 3 shows a graph of points representing observations of salt used and snowfall in inches in a given week. A fitted line is superimposed on these points. This figure shows that as the snow increases, the amount of salt used also increases. Another similar graph of points representing the days of snowfall and the corresponding salt usage is shown in Figure 4. Days of snowfall (in a week) take discrete values from 0 to 7 days, but usage shows a similar increase as days of snowfall increase. From these two figures we see that a noticeable relationship exists between these weather variables and salt usage.

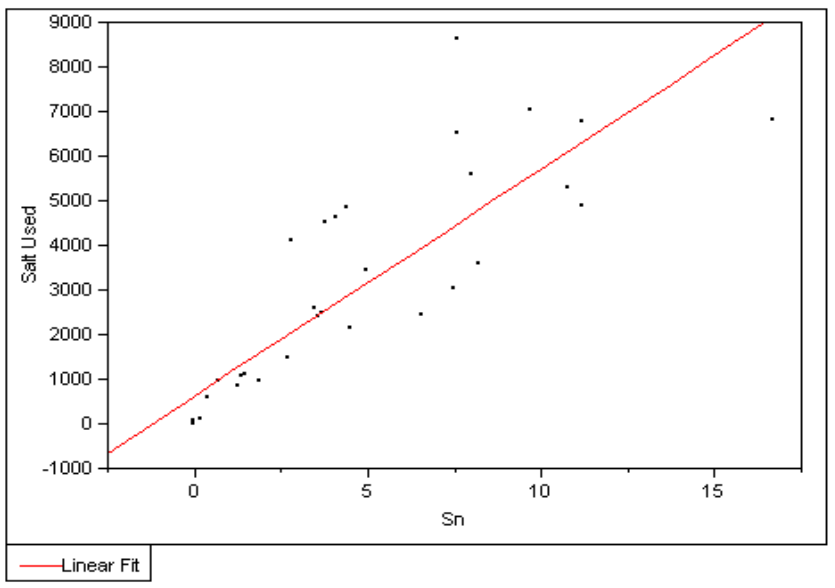

Figure 3 Salt Usage in a State County vs. Snowfall (inches) in January 


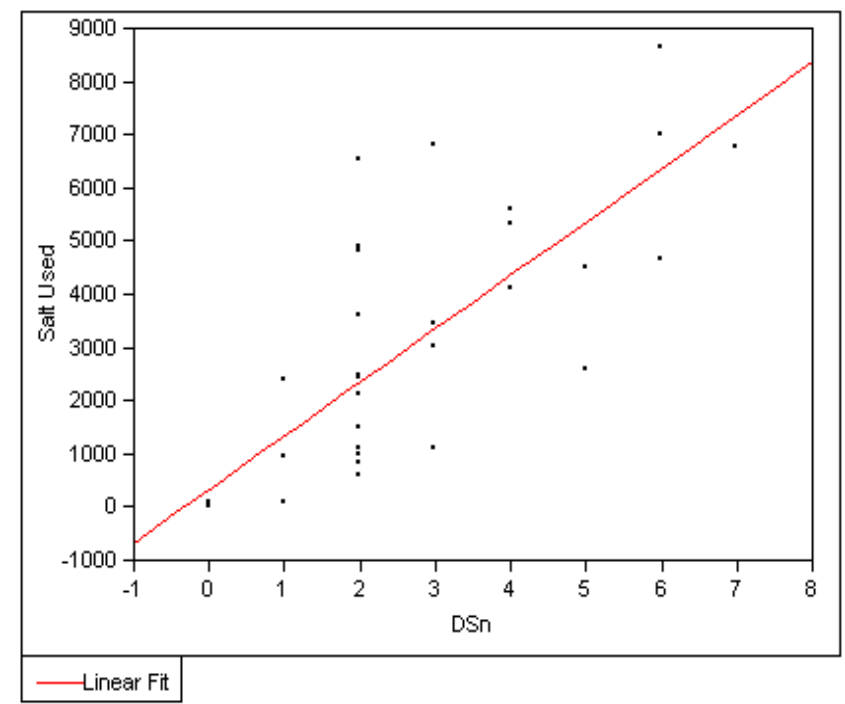

Figure 4 Salt Usage in a State County vs. Number of Days of Snowfall in January

\subsection{Development of weather regression model in Yahoga County}

A model was developed for each of the months, using data over the 7 years. Each month's significant variables for each combination of snowfall and temperature alternatives were found. These combination of variable alternatives consist of the temperature $<30^{\circ} \mathrm{F}$ and snowfall $>.001$ inches, temperature $<30^{\circ} \mathrm{F}$ and snowfall $>0$ inches, temperature $<32^{\circ}$ $\mathrm{F}$ and snowfall $>0$ inches, and temperature $<32^{\circ} \mathrm{F}$ and snowfall $>.001$ inches. Overall it was found that for Yahoga (hypothetical name) County the model performs best when the temperature variable used is $\left\langle 30^{\circ} \mathrm{F}\right.$ and the snowfall variable used is snowfall $>.001$ inches. The only difference is in the model for March where instead of using the temperature $<30^{\circ}$ $\mathrm{F}$ and snowfall > .001 in., the combination of temperature < $32^{\circ} \mathrm{F}$ and snowfall $>.001$ in. are used. Under this condition for the month of March the variables being utilized are Sn, DSn, BSn, and AveT. The variables under these conditions that are most significant are marked with an $\mathrm{X}$ (or the boundary value used is shown) in the appropriate column of Table 2 along with the corresponding $R^{2}$. The table shows that every $R^{2}$ is above .90 and thus the model provides a very good fit.

Table 2 Yahoga County Weather Variables Used for the Regression Model

\begin{tabular}{|llllllllllll|}
\hline Month & Sn & DSn & FzR & BSn & SnC & MaxT & MinT & AveT & R $^{2}$ & R $^{2}$ Adj. & MSE \\
\hline Nov. & $>.001$ & $>.001$ & & & & $<30$ & $<30$ & $<30$ & 0.991 & 0.989 & 10200 \\
Dec. & $>.001$ & $>.001$ & $\mathrm{X}$ & & $>.001$ & & & & 0.921 & 0.911 & 561000 \\
Jan. & $>.001$ & & $\mathrm{X}$ & & & & & $<30$ & 0.951 & 0.944 & 461000 \\
Feb. & $>.001$ & $>.001$ & $\mathrm{X}$ & $\mathrm{X}$ & & $<30$ & & $<30$ & 0.937 & 0.919 & 200000 \\
Mar. & $>.001$ & $>.001$ & & $\mathrm{X}$ & & & & $<32$ & 0.927 & 0.914 & 277000 \\
\hline
\end{tabular}

The models for Yahoga County using the variables as depicted by Table 2 are utilized in determining the predicted values of salt usage. These numbers will be used to calculate the $(R, S)$-inventory guideline values. A model was constructed for each month and is shown below.

$$
\begin{aligned}
\text { Cloveland }_{\text {nov. }}= & 22.001+283.73 * \mathrm{Sn}+129.63 * \mathrm{DSn}- \\
& 997.74 * \mathrm{MaxT}-50.077 * \mathrm{MinT}+ \\
& 1255.4 * \mathrm{AveT} \\
\text { Cloveland }_{\text {dec. }}= & -287.88+255.94 * \mathrm{Sn}+357.68 * \mathrm{DSn} \\
& +761.25 * \mathrm{FzR}+300.87 * \mathrm{SnC} \\
\text { Cloveland }_{\text {jan. }}= & -481.49+472.60 * \mathrm{Sn}+1253.0 * \mathrm{FzR} \\
& +238.55 * \mathrm{AveT} \\
\text { Cloveland }_{\text {feb. }}= & -63.303+256.88 * \mathrm{Sn}+191.81 * \mathrm{DSn} \\
& +355.09 * \mathrm{FzR}+669.02 * \mathrm{BSn}- \\
& 182.39 * \mathrm{MaxT}+139.69 * \mathrm{AveT} \\
= & -118.80+197.75 * \mathrm{Sn}+347.23 * \mathrm{DSn} \\
& +559.45 * \mathrm{BSn}-148.97 * \mathrm{SnC}+ \\
& 223.73 * \mathrm{AveT}^{\text {Cloveland }_{\text {mar. }}}
\end{aligned}
$$

Using the above models the predicted amount of salt used is calculated for each month for each county and is shown in Figures 5-9, along with the actual amount of salt used each month over the 7 year period. Each graph represents the result from a different monthly model, for each of the 5 months. Figure $\mathbf{1 0}$ then shows the actual vs. predicted from November 1998 - March 2005.

Following the same methodology as described for deriving the Yahoga regression model, the other county models and variables were derived. Recall that for each county, there is a unique regression model for predicting salt usage for each month of the winter season. The models are used for establishing the $(R, S)$-inventory guideline parameters and also to establish common climate zones so that only a few models may be used instead of one for each county.

\subsection{Models Based on Climate Zones in the State}

There are close to 80 counties (hypothetical number) in the State. Based on the procedure in the preceding analysis there would need to be 80 separate weather regression models to predict salt usage in each county. To lower the volume of data and effort required to develop and maintain the models a 
common model could be used for counties that are in the same region of the state. This is based on the assumption that the salt usage model is driven by a combination of weather characteristics, and how local guidelines and conditions respond to the weather. The weather regression model is used to calculate predicted usage values for the calculation of the $(R, S)$-inventory guideline. The method to test for these regional models is to: 1 . accumulate the relevant weather variables for the new county, and 2. insert them into a weather regression model of a nearby county. This will result in predictions for the new county based on the regression parameters from the nearby county. These predictions will ultimately be used in the $(R, S)$ calculations.

Three counties were studied to see if the models created for use in that representative county can be used in another county. Error! Not a valid bookmark self-reference. lists the different scenarios tested. The three counties are in the northeast part of State, in and around the snow belt. The process consists of taking the weather regression model parameters originally developed for three cities corresponding to three counties in this part of the State and applying each to a different county's weather data: City 3 (Sumit County), City 4 (Yahoga County), and City 5 (Honing County). Figure 11 shows the state map. The predictions from the nearby county's model were compared to the predictions from the local model. Because all counties have differing lane miles of roads and assuming that usage is close to linear in lane-miles, a lane mileage conversion is used. The lane mileage conversion generates a predicted value of salt usage from the model and then divides by the number of lane mileage of the original county. This predicts the spread rate of salt per lane mile. This number is then be multiplied by the lane mileage of the intended county for predicted salt usage in the intended county.

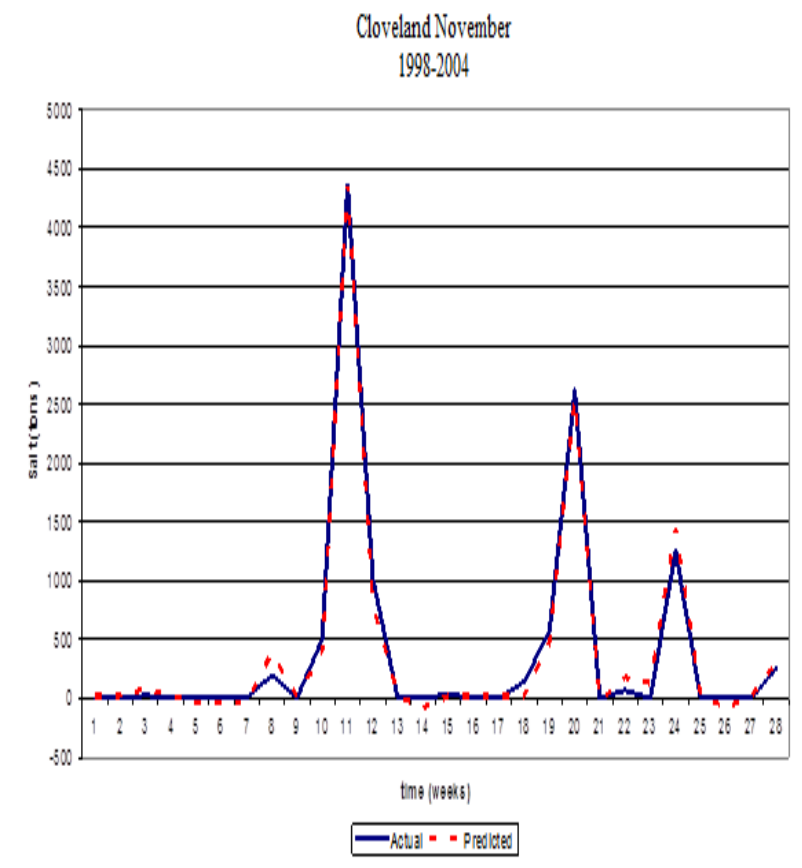

Figure 5 Yahoga November Actual and Predicted Usage

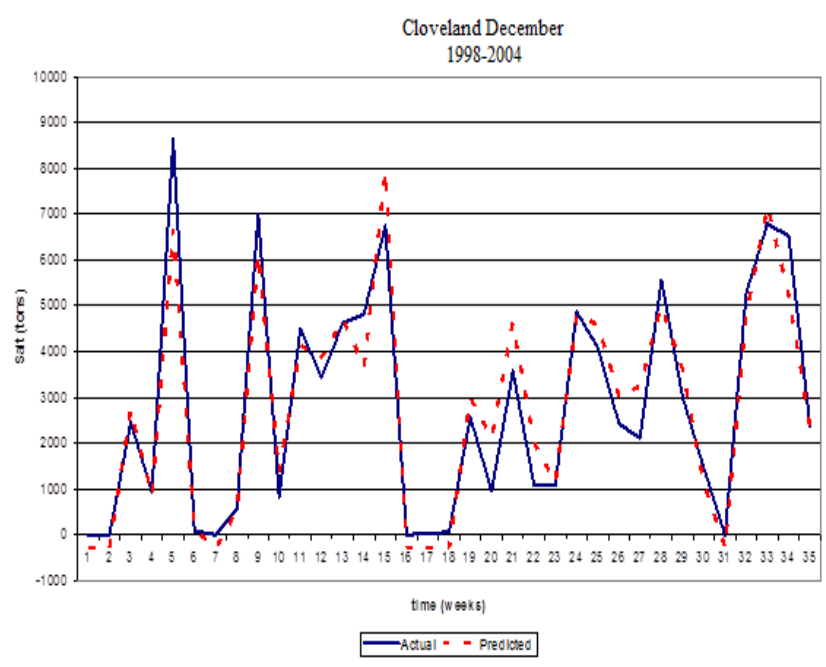

Figure 6 Yahoga December Actual and Predicted Usage

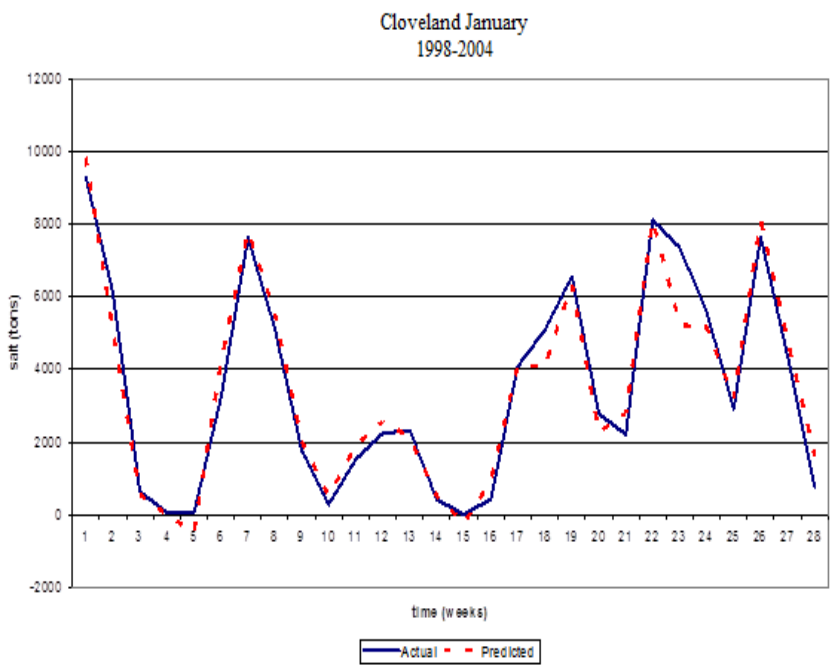

Figure 7 Yahoga January Actual and Predicted Usage

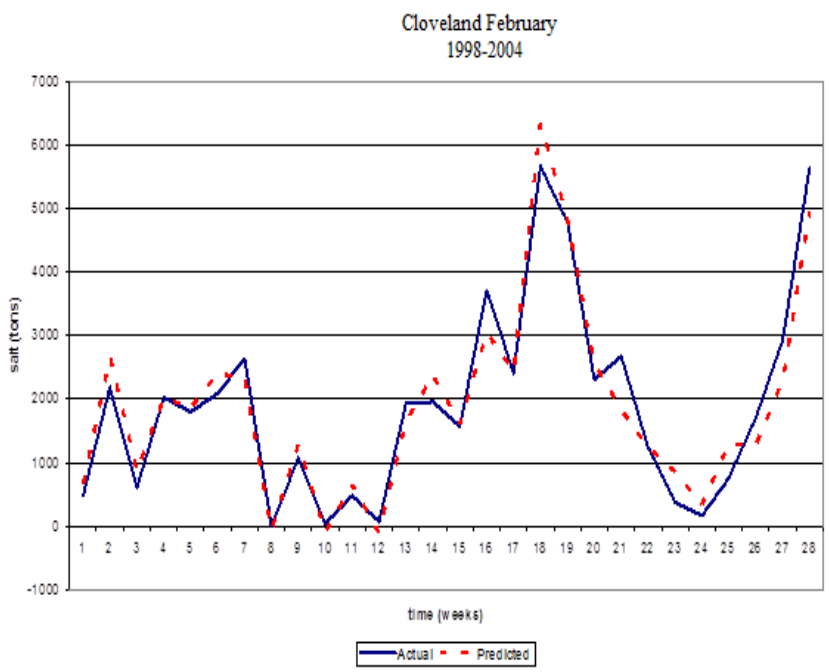

Figure 8 Yahoga February Actual and Predicted Usage 


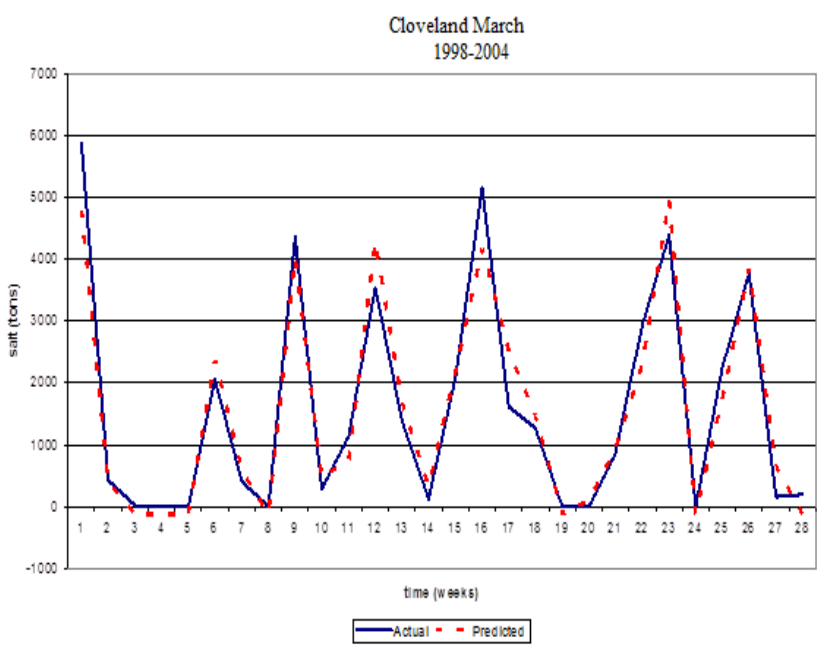

Figure 9 Yahoga March Actual and Predicted Usage

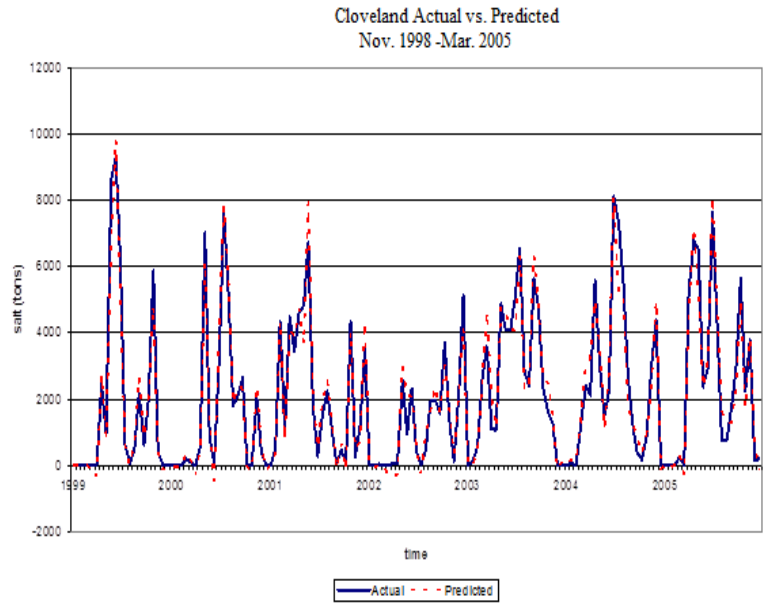

Figure 10 Yahoga November 1998 - March 2005 Actual and Predicted Usage

Table 3 Regression Scenarios Tested

\begin{tabular}{|l|l|l|}
\hline $\begin{array}{c}\text { County } \\
\text { (hypothetical) }\end{array}$ & Scenario\# & \multicolumn{1}{c|}{ Scenarios } \\
\hline Sumit & 1 & Sumit weather model with Sumit weather data \\
\hline & 2 & Yahoga weather model with Sumit weather data taking into account percent difference in lane miles \\
\hline & 3 & Honing weather model with Sumit weather data taking into account percent difference in lane miles \\
\hline Yahoga & 4 & Yahoga weather model with Yahoga weather data \\
\hline & 5 & Sumit weather model with Yahoga weather data taking into account percent difference in lane miles \\
\hline & 6 & Honing weather model with Yahoga weather data taking into account percent difference in lane miles \\
\hline Honing & 7 & Honing weather model with Honing weather data \\
\hline & 8 & Sumit weather model with Honing weather data taking into account percent difference in lane miles \\
\hline & 9 & Yahoga weather model with Honing weather data taking into account percent difference in lane miles \\
\hline
\end{tabular}

From the comparisons it was found that the temperature and snowfall variations used in the original model for the original county must also be used for the new county. For example if the model created for Yahoga was created using "temperature $<30^{\circ} \mathrm{F}$ " and "snowfall $>.001$ inches", then when the model is used for Sumit County the same variables must be included. An additional finding is that models are most accurate when used in other counties with smaller lane mileage. This was found through comparing mean squared errors. These comparisons are listed in Table 4, where Yahoga has the largest number of lane miles followed by Sumit and then Honing. For example a model created for Sumit is not appropriate to predict salt for Yahoga County (a large lane-mile county) even with the lane mileage conversions. The result of using Sumit County for predictions in Yahoga County is an extreme under prediction. Finally, from the comparisons it was found that the models developed directly for a county using local weather and usage data work the best, but utilizing a larger county's weather regression model on a smaller county in a similar weather zone also performs well. This supported our belief that weather regression models developed for one county in a similar weather zone can be used for other counties in the same zone.
A rough description of the weather zones are shown in the map of State (modified from original) in Figure 11. Figure 11 was constructed from the average annual snowfall graph from the State Department of Transportation.

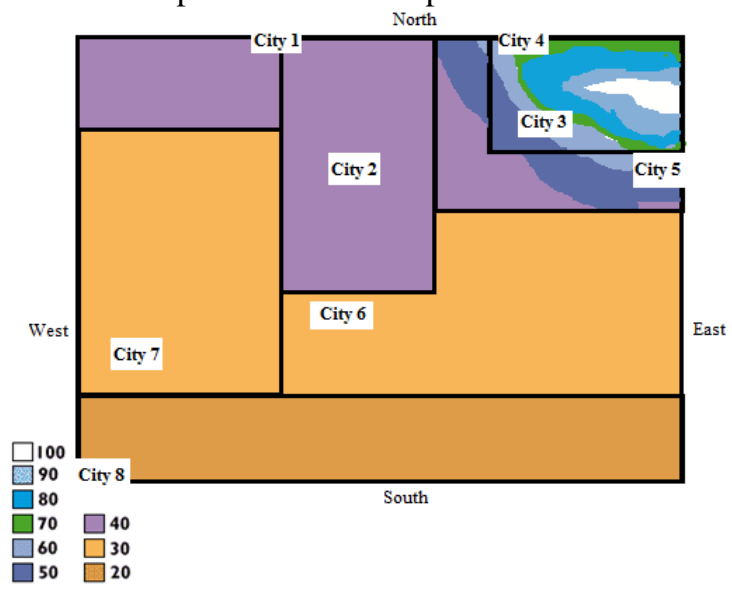

Figure 11 Map of State with Climate Zones

Specifically it was found that City 3 and 4 are in similar weather climates and that the model created for City 4 can be used for City 3 . This was determined by comparing the mean 
squared errors of the three alternatives: Yahoga's model used on Sumit County, Honing model used on Sumit, and the use of Sumit's model. The results of the mean squared errors of the predictions are shown in Table 4.

In summary, the use of the Sumit County model is the best performer, but using the Yahoga County model on the Sumit data performs adequately. The model created for Honing and used on Sumit did not perform as well. This fact reinforces the finding that models from counties with fewer lane miles do not perform well when used on larger counties even when taking into account the lane miles. Figure 12 compares the actual usage with the predictions from City 3 using the City 3 model and using the City 4 model during the month of November. From Figure $\mathbf{1 2}$ it is hard to see the City 3 predictions because the predictions are so close to the actual numbers, but the graph for the City 4 model compared to the actual usage shows just how accurately the model predicts the spikes in demands. Figure 13 compares the model predictions vs. the actuals for all November weeks for each year over the 7 years in our data.

Table 4 Mean Squared Error for Regression Scenarios

\begin{tabular}{|l|lllll|}
\hline \multicolumn{7}{|c|}{ Mean Square Errors } \\
\hline Scenario & November & December & January & February & March \\
\hline 1 & 91.6 & 118000 & 174000 & 109000 & 50200 \\
2 & 54000 & 238000 & 513000 & 175000 & 153000 \\
3 & 517000 & 408000 & 1110000 & 302000 & 178000 \\
4 & 10200 & 561000 & 461000 & 200000 & 277000 \\
5 & 285000 & n/a & 1270000 & n/a & n/a \\
6 & 511000 & n/a & 3090000 & n/a & n/a \\
7 & 3420 & 288000 & 449000 & 208000 & 107000 \\
8 & 82600 & 455000 & 1040000 & 561000 & 202000 \\
9 & 46400 & 396000 & 1410000 & 724000 & 318000 \\
\hline
\end{tabular}

\section{THE $(R, S)$-INVENTORY GUIDELINE}

The $(R, S)$-inventory parameters are calculated by taking the predictions of salt usage from the weather regression models for all counties as detailed in section 4 , and finding the mean usage during the lead time and the representative standard deviations. These numbers can also be calculated simply by taking the historical data and performing the same calculations. The historical usage data can be used to calculate the $(R, S)$-inventory guideline if relevant weather data is not available.

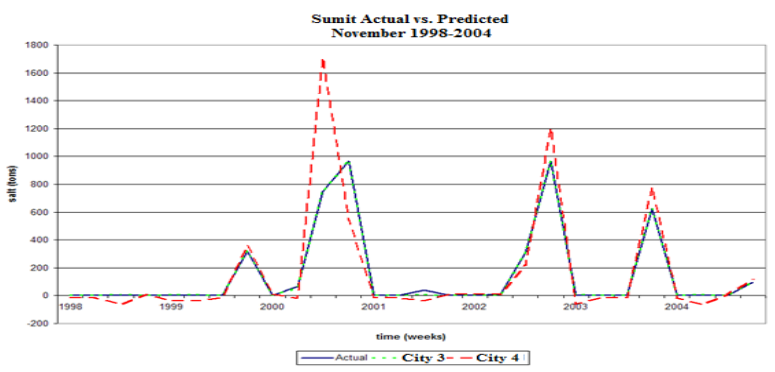

Figure 12 Actual vs. Predicted for Sumit County in November

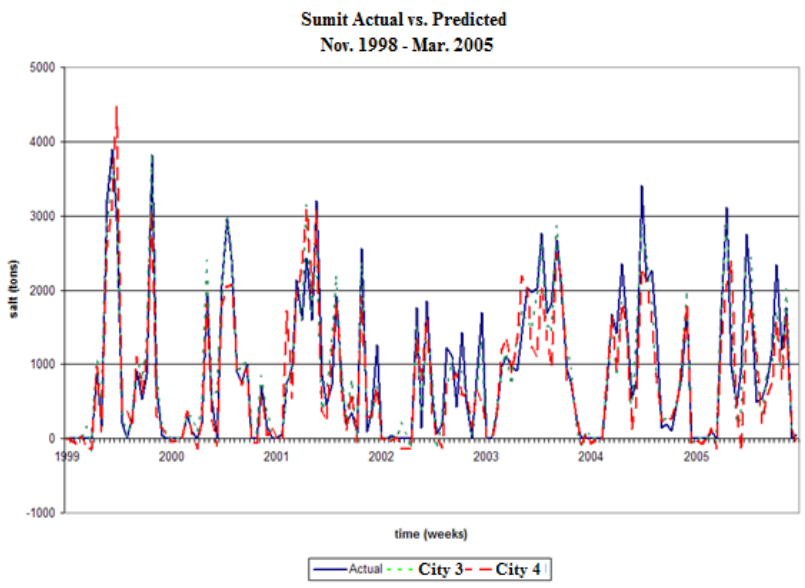

Figure 13 Actual vs. Predicted for Sumit County for 7 Years

\subsection{The (R, S)-Inventory Guideline Calculations}

The $(R, S)$-inventory guideline parameters are calculated by finding the mean and standard deviation of the weekly salt usage prediction values for each month which were calculated from the weather regression models. The data was already accumulated into weeks as the delivery lead time is also one week. A service level of $99.8 \%$ is used for the calculation of the safety stock and thus $k$ in equation (2) is 2.88 and the safety stock equation is: $s s=2.88 \sigma_{L T}$. The mean usage during the lead time $\left(\mu_{L T}\right)$ (which is the expected weekly demand) is found by taking the mean of the weekly data collected from each month. The reorder point $(R)$ is calculated by equation (1). The target level $(S)$ is computed using equation (3). The inventory guideline for Yahoga county is presented in the following section with the calculations of the safety stock $(s S)$, the reorder point $(R)$, and the target level $(S)$.

\subsection{The (R, S)-Inventory Guideline for Yahoga County}

Table 5 shows the safety stock for Yahoga calculated by taking the standard deviation of the predictions for each month, and multiplied by 2.88 which results in a $99.8 \%$ safety level. The safety stock is the amount of inventory held to mitigate the effect of uncertainties in demand, such as a severe storm that would cause a spike in usage above the average. Table 5 also shows the mean or expected usage during the lead time. Finally

Table 5 provides the point at which the county will reorder $(R)$ during each month and also the target level for inventories for each month. The target level $(S)$ determines the amount to order. Equation (4) displays the equation for the amount to be ordered $(Q)$. The equation is the target level $(S)$ minus the current inventory level $(I)$. An order is placed when current inventory $(I)$ drops below the reorder point $(R)$. $Q=S-I$ 
For example in the December, when inventory, $I$, drops to or below 9700 tons of salt, $(12,600-I)$ tons of salt is ordered.

Table $5(R, S)$-Inventory Guideline Values for Yahoga County

\begin{tabular}{|c|c|c|c|c|c|c|}
\hline \multicolumn{2}{|l|}{ Months } & Nov & Dec & Jan & Feb & Mar \\
\hline 1 & ss & 2750 & 6930 & 8080 & 4370 & 4920 \\
\hline 2 & $\mu_{L T}$ & 395 & 2820 & 3520 & 1900 & 1560 \\
\hline $3=1+2$ & $R$ & 3140 & 9750 & 11600 & 6280 & 6490 \\
\hline 4 & $E$ (week) & 395 & 2820 & 3520 & 1900 & 1560 \\
\hline $5=3+4$ & $S$ & 3540 & 12600 & 15100 & 8180 & 8050 \\
\hline
\end{tabular}

\subsection{The (R, S)-Inventory Guideline Values for Sumit County}

In 4.4 section 4.4, two regression models for Sumit County were proposed, and these were used to develop two $(R, S)$-inventory guidelines. It was found from comparisons between mean squared errors using the Sumit weather regression model for Sumit and the Yahoga regression model for Sumit that these models were both acceptable. The regression model only predicts salt usage, but these values are then used to derive the $(R, S)$-inventory guideline. Table 6 and Table 7 show the results for Sumit based on the two models.

Table $6(R, S)$-Inventory Guideline Values for Sumit Using the Sumit Model

\begin{tabular}{|c|c|c|c|c|c|c|}
\hline \multicolumn{2}{|l|}{ Months } & Nov & Dec & Jan & Feb & Mar \\
\hline 1 & ss & 863 & 2750 & 3060 & 1800 & 2580 \\
\hline 2 & $\mu_{L T}$ & 149 & 1150 & 1580 & 889 & 707 \\
\hline $3=1+2$ & $R$ & 1010 & 3900 & 4640 & 2690 & 3290 \\
\hline 4 & $\mathrm{E}$ (week) & 149 & 1150 & 1580 & 889 & 707 \\
\hline $5=3+4$ & $S$ & 1160 & 5040 & 6220 & 3580 & 3990 \\
\hline
\end{tabular}

Table $7(R, S)$-Inventory Guideline Values for Sumit Using the Yahoga Model

\begin{tabular}{|c|c|c|c|c|c|c|}
\hline \multicolumn{2}{|l|}{ Months } & Nov & Dec & Jan & Feb & Mar \\
\hline 1 & SS & 1200 & 2920 & 3080 & 1680 & 2100 \\
\hline 2 & $\mu L T$ & 163 & 1130 & 1280 & 743 & 573 \\
\hline $3=1+2$ & $R$ & 1370 & 4050 & 4360 & 2430 & 2670 \\
\hline 4 & $\mathrm{E}$ (week) & 163 & 1130 & 1280 & 743 & 573 \\
\hline $5=3+4$ & $S$ & 1530 & 5170 & 5630 & 3170 & 3240 \\
\hline
\end{tabular}

Comparing Tables 5.2 and 5.3, it is evident that all the safety stocks with the exception of February and March are higher with use of the Yahoga model. These values are an indication that the weather in the area is very unpredictable and more safety stock is required to minimize the chance of a salt stockout. The values are relatively close with the maximum percent difference of $35.6 \%$ for the reorder point and $31.9 \%$ for the stock target level in the month of November. The average percent difference is $.986 \%$ and -
$1.06 \%$ for the reorder point and stock target level respectively. There is some concern with the values for January, February, and March because the distance between these two values represent the frequency and the amount of orders. The reorder points and the stock target levels which depict the amount to order for these months are somewhat low as in Table 7. To answer the question as to how well the two models perform when implemented, a simulation model is used in section 6 to test the performance of the guidelines in a more realistic setting.

A study of the adjacent week's usage data was carried out to confirm that the data did not have significant correlation. For weekly data from Yahoga County, the estimated correlation coefficient is 0.478 for a distance of one week and -0.011 for a distance of two weeks. As a result the data points used to build the weather regression model and thus the $(R$, $S$ )-inventory guideline have reasonably low correlation. Also, it is worthwhile to note that combining together 7 daily demands and multiple garage locations in a county improves the "normality" of the weekly usage. Further impacts of these assumptions on the performance of the guidelines are evaluated using a simulation approach in the following section.

\section{THE SIMULATION MODEL}

A detailed study of the performance of the $(R, S)$ inventory guidelines using an Arena (Kelton et al., 2004) simulation model was studied. First, we studied the effects of implementing the guideline in Yahoga County based on actual usage from 1998 - 2005. We also studied whether a model originally developed for one county can be used effectively in another county. This will be studied using Sumit County.

\subsection{Simulation Development}

A simulation model was constructed to study the effects of implementing the $(R, S)$-inventory guideline in a realistic setting. The simulation is driven by actual historical salt usage data or by simulated demands. A simulation is a good way of studying a real life condition by allowing experiments with the model as compared to experiments in a real world situation. The goals of the simulation study are to: i) test the actual performance of the suggested $(R, S)$ guidelines vs. the predicted performance in terms of service level, ii) compare the suggested $(R, S)$ guidelines to current practice and identify any factors that have not been considered in the design, and iii) from the salt vendor perspective compare the stream of orders generated by the current practice and the orders generated by the $(R, S)$ guideline.

One of the important differences between the $(R, S)$ guideline and the current practice, is that in current practice the goal is to keep the garage storage capacity as close to full as possible at all times, including at the beginning and end of the season. The simulation is used to compare the two approaches from the perspective of inventory levels and service level. The simulation model reads actual salt usage data and then applies the ordering logic of either the $(R, S)$ guideline parameters or other guidelines. Figure 14 shows 
the structure of the model with the flow of salt from the vendor to the garage and eventual demand.

In the model there is a delay of two days from the placement of an order by the county garage until the order can begin to be fulfilled. To determine the fulfillment lead time, the order is partitioned into a number of daily deliveries based on the history of actual received amounts for that county. A distribution is fit to the actual delivered data and is used to drive the fulfillment process in the model. A rough estimate on the number of days an order takes to fully deliver is to take the full order amount and divide by the maximum that can be received each day and add two days.

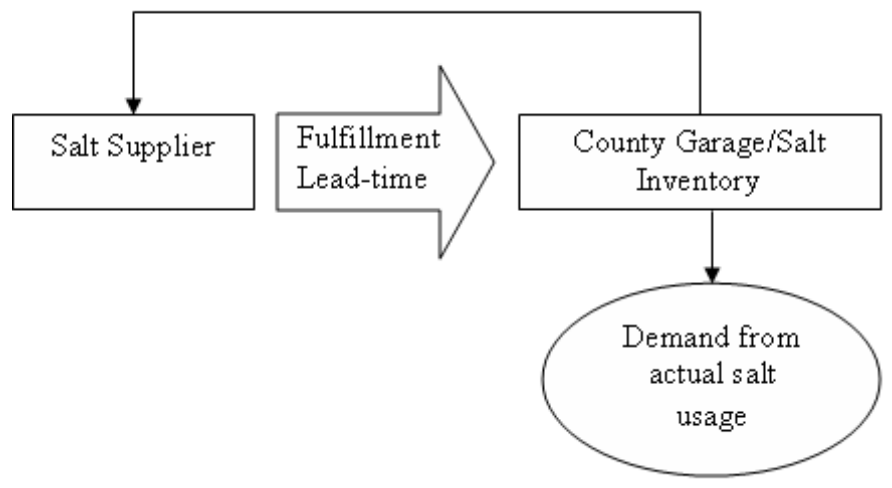

Figure 14 Salt Order Fulfillment and Usage Flow Diagram

From the actual state contracts with the suppliers, orders must be filled within 7 days. In reality the time to completely fulfill an order is dependent on many factors, including the availability of trucks and the availability of resources at the county garages to receive the salt. Because of these complicating factors it is important to model deliveries to the county garage with an appropriate level of detail. Because of the use of a probability distribution to drive the rate of delivery for an order, the simulation creates some scenarios where deliveries are delayed beyond the 7-day contract guideline. These simulated scenarios stress the guidelines, in some cases beyond what has been experienced historically. These cases help determine which guidelines deal with both situations that have existed in the past, as well as new, worstcase scenario situations, where usage is very high, and replenishment is slower than expected.

The order streams from the simulation can be compared with actual order amounts. The level of inventory from the simulation can be compared to the actual level of the inventory observed in the years of the historical demand. The actual inventory levels are computed by the simulation model using actual received, used, and beginning inventories to generate results in the same format for easy comparisons.

To study variations in the computed $(R, S)$ guidelines that match some of the guidelines used in practice, the following initial conditions and guideline variations were considered for November, December, and January. Initial inventory on November $1^{\text {st }}$ has 5 options: i) inventory reported in the state DOT database for Nov. 1, ii) target level (S) from $(R, S)$ guideline for November, iii) target level (S) from $(R, S)$ guideline for March, iv) target level $(\mathrm{S})$ from $(R, S)$ guideline for December, and v) target level (S) from $(R, S)$ guideline for January. The initial inventories for the $(R, S)$ guidelines were varied in this way to test the $(R, S)$ guidelines directly and also to test the variations possible when the guideline is implemented. There were 3 guideline variations considered over for the five months of the study: i) guideline computed in Section 5.2 for all months, ii) guideline computed from Section 5.2 is used, but the guideline begins a number of days in the preceding month for December, January, February and March, and iii) guideline computed from Section 5.2 is used, but the guideline begins a number of days early for December and January only.

The guidelines were varied in this way as stated above because the simulation showed that large orders were made when changing from one month's guideline to the next month. This was the case especially when going from a lower reorder point and stock target level to one that is higher. As a result it would take up to one week for a garage to reach its stock target level for that month. By beginning months seven days into the preceding month a month would start off with close to its stock target level. The guidelines for the months of the study were varied to mimic the very conservative guidelines currently followed in practice. The most conservative guideline uses the January inventory target level for the beginning inventories for November and uses the January reorder point and target level for part of the month of December and all of January. This is conservative because January is the highest usage month historically.

Two counties were considered in the simulation experiments: Yahoga and Sumit. The experiment used data for the seven consecutive winter seasons starting with November 1998 - March 1999. Each year was run independently with results tabulated as averages. Although there are 5 garages/domes located in Yahoga, the county was treated as a single inventory location because data for each individual garage was unavailable. Finally, because two $(R$, $S$ )-inventory polices were developed for Sumit County in Section 5.3 using two different weather regression models, the effectiveness of each was studied. The two models for Sumit were calculated by using the Sumit weather regression model on Sumit and then the Yahoga weather regression model used on Sumit to calculate predicted salt usage. These predictions were then used to calculate individual $(R, S)$-inventory guideline parameters for Sumit.

Table 8 Schedule A $(R, S)$ Variations

\begin{tabular}{|l|l|}
\hline Schedule A & Schedule \\
\hline Month & November guideline \\
December guideline & December 1 to November $30^{\text {th }}$ \\
January guideline & January $1^{\text {st }}$ to January $31^{\text {st }}$ \\
February guideline & February $1^{\text {st }}$ to February $28^{\text {th }}$ \\
March guideline & March $1^{\text {st }}$ to March $31^{\text {st }}$ \\
\hline
\end{tabular}


To effectively deal with up to one week of delivery lead time, the monthly $(R, S)$ guidelines were varied based on the two schedules in Table 6.2 and Table 6.3 respectively.

Table 9 Schedule B $(R, S)$ Variations

\begin{tabular}{|l|l|}
\hline Schedule B & Schedule \\
\hline Month & November $1^{\text {st }}$ to November $23^{\text {rd }}$ \\
December guideline & November $24^{\text {th }}$ to December $24^{\text {th }}$ \\
January guideline & December $25^{\text {th }}$ to January $24^{\text {th }}$ \\
February guideline & January $25^{\text {th }}$ to February $21^{\text {st }}$ \\
March guideline & February $22^{\text {nd }}$ to March $31^{\text {st }}$ \\
\hline
\end{tabular}

Based on Schedules B and C, the starting inventories on the first of the month are more likely to be the target $(S)$ value for that month. This works well in cases where the target level increases, but for those months where the target level decreases this is not possible, and it is possible that a location is "overstocked" with respect to its inventory guideline at the beginning of a month.

Table 10 Schedule $\mathrm{C}(R, S)$ Variations

\begin{tabular}{|l|l|}
\hline Schedule C & Schedule \\
\hline Month & November $1^{\text {st }}$ to November $23^{\text {rd }}$ \\
November guideline & November $24^{\text {th }}$ to December $24^{\text {th }}$ \\
January guideline & December $25^{\text {th }}$ to January $31^{\text {st }}$ \\
February guideline & February $1^{\text {st }}$ to February $28^{\text {th }}$ \\
March guideline & March $1^{\text {st }}$ to March $31^{\text {st }}$ \\
\hline
\end{tabular}

\subsection{Definition of the Guideline Variations}

In Section 6.1 we identified several variations for the beginning inventory levels for November $1^{\text {st }}$ and also have identified some variations of points in time counties should utilize particular months $(R, S)$ values. Table 11 lists all possible variations that were tested through simulation and are identified with a guideline number.

Table 11 Guideline Variations

\begin{tabular}{|c|c|}
\hline $\begin{array}{l}\text { Guideline } \\
\text { Number }\end{array}$ & Definition \\
\hline Actual & $\begin{array}{l}\text { The beginning inventory is actual beginning inventory provided by the state DOT and orders } \\
\text { are actual orders provided by the state DOT }\end{array}$ \\
\hline 1 & $\begin{array}{l}\text { The beginning inventory is actual beginning inventory provided by the state DOT and } \\
\text { mplementing Schedule A }\end{array}$ \\
\hline 2 & \multirow{2}{*}{$\begin{array}{l}\text { The beginning inventory level is the stock target level (S) for November and implementing } \\
\text { Schedule A } \\
\text { The beginning inventory level is the stock target level (S) for December and implementing } \\
\text { Schedule A }\end{array}$} \\
\hline 3 & \\
\hline 4 & \multirow{2}{*}{$\begin{array}{l}\text { The beginning inventory level is the stock target level (S) for January and implementing } \\
\text { Schedule A } \\
\text { The beginning inventory level is the stock target level (S) for March } \\
\text { and implementing Schedule A }\end{array}$} \\
\hline 5 & \\
\hline 6 & \multirow{2}{*}{$\begin{array}{l}\text { The beginning inventory level is the stock target level (S) for November and implementing } \\
\text { Schedule B } \\
\text { The beginning inventory level is the stock target level (S) for December and implementing } \\
\text { Schedule B }\end{array}$} \\
\hline 7 & \\
\hline 8 & \multirow{2}{*}{$\begin{array}{l}\text { The beginning inventory level is the stock target level (S) for January and implementing } \\
\text { Schedule B } \\
\text { The beginning inventory level is the stock target level (S) for March } \\
\text { and implementing Schedule B }\end{array}$} \\
\hline 9 & \\
\hline 10 & \multirow{2}{*}{$\begin{array}{l}\text { The beginning inventory level is the stock target level (S) for November and implementing } \\
\text { Schedule C } \\
\text { The beginning inventory level is the stock target level (S) for December and implementing } \\
\text { Schedule C }\end{array}$} \\
\hline 11 & \\
\hline 12 & \multirow{2}{*}{$\begin{array}{l}\text { The beginning inventory level is the stock target level (S) for January and implementing } \\
\text { Schedule C } \\
\text { The beginning inventory level is the stock target level (S) for March } \\
\text { and implementing Schedule C }\end{array}$} \\
\hline 13 & \\
\hline
\end{tabular}




\subsection{Simulation Results for Yahoga County}

Simulations were run for every year 1998 through 2005, for each of the guidelines listed in Table 6.4 for Yahoga County. Each guideline was evaluated using 30 replications with random variations added to the supply process to induce some "worst case scenarios". These random "worst-case" supply scenarios result in longer than average resupply delivery times. When combined together with the historical usage scenarios, this worst-case supply methodology "stresses" the inventory management guidelines beyond what we expect to see in actual practice. For example, in these worst-case scenarios, the re-supply lead time to fill an order can extend several days beyond the 7-day guideline. Combined with an extended period of high usage, these worstcase scenarios show the limits of the suggested inventory guidelines. To find the best guideline, we looked at the average number of stockouts in the simulated scenarios for each year and accumulated them over the years for each guideline. We also looked at average inventories, number of orders placed and received, order size, and also the average of the minimum season-long inventories. The number of orders received was the total number of truckload deliveries received at the county garage, while the number of orders placed was the total number of orders placed to the vendor.

To compare the guidelines we first ran the simulation with the actual used, received, and beginning inventories data supplied by the state DOT for years from $1999-2005$. The results of the runs over the 7 years are shown in Table 12.

Table 12 Simulation Results with Actual Data for Yahoga 1999 2005

\begin{tabular}{|l|l|l|l|l|}
\hline Year & $\begin{array}{l}\text { Number of } \\
\text { Stockouts }\end{array}$ & $\begin{array}{l}\text { Ave. } \\
\text { Inventory } \\
\text { level }\end{array}$ & $\begin{array}{l}\text { Ave. } \\
\text { Amount } \\
\text { Received }\end{array}$ & $\begin{array}{l}\text { Ave.\# of } \\
\text { Order } \\
\text { Received }\end{array}$ \\
\hline 2005 & 0 & 12900 & 860 & 46 \\
2004 & 0 & 21000 & 937 & 40 \\
2003 & 0 & 15900 & 796 & 57 \\
2002 & 0 & 21200 & 603 & 39 \\
2001 & 0 & 12400 & 704 & 59 \\
2000 & 0 & 13100 & 781 & 37 \\
1999 & 0 & 14100 & 691 & 45 \\
\hline
\end{tabular}

Utilizing the actual beginning inventories and the actual historical used salt amounts provided by the state DOT, we then ran the simulation for guideline 1 .

This guideline used the given numbers and implements the $(R, S)$-inventory guideline. From Table $\mathbf{1 3}$ we see that just by implementing the $(R, S)$-inventory guideline with the actual beginning inventories we reduced the average inventories in all years and in some cases even decreased the number of orders received. This can be seen in Figure 15 where the inventory levels for the actual are graphed against guideline 1.

Table 13 Simulation Results for Guideline 1 for Yahoga 1999 - 2005

\begin{tabular}{|c|c|c|c|c|c|c|c|c|c|c|c|c|}
\hline Year & Policy & $\begin{array}{l}\text { Ave. \# of } \\
\text { Stockouts }\end{array}$ & $\stackrel{ \pm}{\mathrm{Cl}}$ & $\begin{array}{l}\text { Ave. } \\
\text { Inv. } \\
\text { Level }\end{array}$ & $\stackrel{ \pm}{\mathrm{Cl}}$ & $\begin{array}{l}\text { Ave. \# of Orders } \\
\text { Placed }\end{array}$ & $\stackrel{ \pm}{\mathrm{Cl}}$ & $\begin{array}{l}\text { Ave. Amt. } \\
\text { Received }\end{array}$ & $\begin{array}{l} \pm \\
\mathrm{Cl}\end{array}$ & $\begin{array}{l}\text { Ave. \# of } \\
\text { Order Rec }\end{array}$ & $\stackrel{ \pm}{\mathrm{Cl}}$ & $\begin{array}{l}\text { Ave. } \\
\text { Min. } \\
\text { Inv. }\end{array}$ \\
\hline 2005 & 1 & 0 & 0 & 12500 & 123 & 12.7 & 0.31 & 850 & 34.7 & 49.5 & 2.32 & 11200 \\
\hline 2004 & 1 & 0 & 0 & 15700 & 216 & 9.2 & 0.33 & 854 & 54.7 & 35.5 & 2.14 & 14400 \\
\hline 2003 & 1 & 0 & 0 & 12400 & 115 & 13.0 & 0.32 & 823 & 35.3 & 48.1 & 2.31 & 11300 \\
\hline 2002 & 1 & 0 & 0 & 12700 & 16.1 & 7.2 & 0.14 & 826 & 51.3 & 18.5 & 1.08 & 12500 \\
\hline 2001 & 1 & 0 & 0 & 10500 & 148 & 12.4 & 0.30 & 839 & 36.9 & 46.2 & 2.11 & 9490 \\
\hline 2000 & 1 & 0 & 0 & 11900 & 65.7 & 8.1 & 0.18 & 848 & 49.4 & 28.7 & 1.78 & 11500 \\
\hline 1999 & 1 & 0.1 & 0.15 & 13300 & 162 & 8.3 & 0.17 & 861 & 55.1 & 33.3 & 2.15 & 12100 \\
\hline
\end{tabular}

We also systematically explored the impact of beginningof-season inventories. We did this by running the different guidelines with different initial stock target levels in November calculated from section 5.2 for Yahoga County. We first tested the stock target level for November as the beginning inventory level on November $1^{\text {st }}$ by running guideline 2,6, and 10. We found that beginning the year with November's target level gave the largest number of stockouts on average over the years. Table 14 shows the results of the simulations. Each year's result is averaged to get a 7 years average. The stockouts for each year are summed to get a total number of average stockouts for the 7 years.
Table 14 Simulation Results for Yahoga for Guidelines with November Target Level

\begin{tabular}{|l|c|c|c|c|c|c|}
\hline $\begin{array}{c}\text { Guidel } \\
\text { ine }\end{array}$ & $\begin{array}{c}\text { Total \# of } \\
\text { Ave. } \\
\text { Stockout } \\
\text { s }\end{array}$ & $\begin{array}{c}\text { Ave. } \\
\text { Inv. } \\
\text { Level }\end{array}$ & $\begin{array}{c}\text { Ave. \# of } \\
\text { Orders } \\
\text { Placed }\end{array}$ & $\begin{array}{c}\text { Ave. } \\
\text { Amt. } \\
\text { Receiv } \\
\text { ed }\end{array}$ & $\begin{array}{c}\text { Ave. \# } \\
\text { of } \\
\text { Order } \\
\text { Rec. }\end{array}$ & $\begin{array}{c}\text { Ave. } \\
\text { Min. } \\
\text { Inv. }\end{array}$ \\
\hline 2 & 4.10 & 7580 & 14.8 & 840 & 57.7 & 6050 \\
6 & 2.43 & 7890 & 14.5 & 845 & 57.2 & 6340 \\
10 & 2.43 & 8180 & 13.7 & 855 & 56.8 & 6650 \\
\hline
\end{tabular}


The November $(R, S)$ stock target level for Yahoga County is 3,540 tons, which is less than the 8,050 ton stock target level for the month of March. To mimic current practice, we considered using the higher March $(R, S)$ target level for November. Utilizing the stock target level for March as the beginning inventory level for guidelines 5, 9, and 13 we found that stockouts on average were reduced. Table $\mathbf{1 5}$ shows the results of using the stock target level of March for the beginning inventory on November $1^{\text {st }}$.

Table 15 Simulation Results for Yahoga for Guidelines with March Target Level

\begin{tabular}{|l|l|l|l|l|l|l|}
\hline $\begin{array}{c}\text { Gui } \\
\text { deli } \\
\text { ne }\end{array}$ & $\begin{array}{c}\text { Total \# of } \\
\text { Ave. } \\
\text { Stockouts }\end{array}$ & $\begin{array}{c}\text { Ave. } \\
\text { Inv. } \\
\text { Level }\end{array}$ & $\begin{array}{c}\text { Ave. \# of } \\
\text { Orders } \\
\text { Placed }\end{array}$ & $\begin{array}{c}\text { Ave. } \\
\text { Amt. } \\
\text { Receive } \\
\text { d }\end{array}$ & $\begin{array}{c}\text { Ave.\# } \\
\text { of Order } \\
\text { Rec. }\end{array}$ & $\begin{array}{c}\text { Ave. } \\
\text { Min. } \\
\text { Inv. }\end{array}$ \\
\hline 5 & 1.73 & 8720 & 12.8 & 843 & 51.7 & 7610 \\
9 & 0.967 & 8870 & 13.8 & 838 & 52.0 & 7590 \\
13 & 0.967 & 9160 & 12.9 & 850 & 51.4 & 8460 \\
\hline
\end{tabular}

Comparing Tables 14 and 15 we found that as beginning inventories were increased total average stockouts decreased, but average and minimum average inventories increased. It is evident from the data in the tables that increasing beginning inventories reduced the number of orders placed and received by changing the average order amounts very little. Though average inventories were lower using the November stock target level it is more important to have no stockouts. These comparisons suggest that among this set of choices, the best alternative is to utilize the March stock target level for the beginning inventory level. The best choice is guideline 9 or 13 because they have the lowest total average number of stockouts. The tie breaker would be the lowest orders placed and the average amount received. This would result in guideline 13, which is the guideline of utilizing the months of December and January's $(R, S)$ guideline numbers seven days into the preceding month. We expect this guideline to be the best choice when we run the simulation with the December and January stock target levels. Table 16 and Table 17 show the results of the simulation using the stock target level of 12,600 for December and 15,100 for January, respectively.
Table 16 Simulation Results for Yahoga for Guidelines with December Target Level

\begin{tabular}{|c|c|c|c|c|c|c|}
\hline $\begin{array}{l}\text { Guid } \\
\text { eline }\end{array}$ & $\begin{array}{c}\text { Total \# of } \\
\text { Ave. } \\
\text { Stockouts }\end{array}$ & $\begin{array}{l}\text { Ave. } \\
\text { Inv. } \\
\text { Level }\end{array}$ & $\begin{array}{l}\text { Ave. \# of } \\
\text { Orders } \\
\text { Placed }\end{array}$ & $\begin{array}{l}\text { Ave. } \\
\text { Amt. } \\
\text { Receiv } \\
\text { ed }\end{array}$ & $\begin{array}{c}\text { Ave. \# } \\
\text { of } \\
\text { Order } \\
\text { Rec. }\end{array}$ & $\begin{array}{l}\text { Ave. } \\
\text { Min. } \\
\text { Inv. }\end{array}$ \\
\hline 3 & 0.90 & 9840 & 12.3 & 836 & 46.7 & 8470 \\
\hline 7 & 0.666 & 9730 & 12.9 & 836 & 46.7 & 8620 \\
\hline 11 & 0.666 & 10000 & 12.1 & 844 & 46.5 & 8980 \\
\hline
\end{tabular}

Table 17 Simulation Results for Yahoga for Guidelines with January Target Level

\begin{tabular}{|l|c|c|c|c|c|c|}
\hline $\begin{array}{c}\text { Guide } \\
\text { line }\end{array}$ & $\begin{array}{c}\text { Total \# of } \\
\text { Ave. } \\
\text { Stockout } \\
\text { s }\end{array}$ & Ave. Inv. & $\begin{array}{c}\text { Ave. \# } \\
\text { of } \\
\text { Order } \\
\text { s } \\
\text { Place } \\
\text { d }\end{array}$ & $\begin{array}{c}\text { Ave. } \\
\text { Amt. } \\
\text { Recei } \\
\text { ved }\end{array}$ & $\begin{array}{c}\text { Ave. \# } \\
\text { of } \\
\text { Order } \\
\text { Rec. }\end{array}$ & $\begin{array}{c}\text { Ave. } \\
\text { Min. } \\
\text { Inv. }\end{array}$ \\
\hline 4 & 1.37 & 10700 & 11.9 & 832 & 44.0 & 9700 \\
8 & 1.23 & 10500 & 12.5 & 830 & 44.1 & 9690 \\
12 & 1.23 & 10800 & 11.6 & 840 & 43.6 & 9700 \\
\hline
\end{tabular}

From Table 16 and Table 17 we conclude that best choice is guideline 11, which uses December stock target level as the beginning inventory. This guideline minimizes the total number of average stockouts with lowest average orders placed and received. When examining the simulation results closer we found that in 1999 every guideline had an average stockout greater than or equal to 0.567 with guidelines 4,8 , and 12 having at least 1.1 stockouts. Based on a meeting with the state DOT officials the results of the simulation are consistent with inventories in 1999. Many counties did see stockouts due to complications in receiving orders. We decided that the two best guidelines found from the simulation runs are guidelines 11 and 12 . The comparisons between the two are shown in Table 18 and Table 19 including confidence intervals.

Table 18 Simulation Results for Guideline 11 for Yahoga 1999 - 2005

\begin{tabular}{|c|c|c|c|c|c|c|c|c|c|c|c|c|}
\hline Year & Policy & $\begin{array}{l}\text { Ave. \# of } \\
\text { Stockouts }\end{array}$ & $\begin{array}{l} \pm \\
\mathrm{Cl}\end{array}$ & $\begin{array}{l}\text { Ave. } \\
\text { Inv. } \\
\text { Level }\end{array}$ & $\begin{array}{l} \pm \\
\mathrm{Cl}\end{array}$ & $\begin{array}{l}\text { Ave. \# of Orders } \\
\text { Received }\end{array}$ & $\begin{array}{l} \pm \\
\mathrm{Cl}\end{array}$ & $\begin{array}{c}\text { Ave. Amt. } \\
\text { Ordered }\end{array}$ & $\begin{array}{l} \pm \\
\mathrm{Cl}\end{array}$ & $\begin{array}{l}\text { Ave. \# of } \\
\text { Order Rec. }\end{array}$ & $\begin{array}{l} \pm \\
\mathrm{Cl}\end{array}$ & $\begin{array}{l}\text { Ave. } \\
\text { Min. } \\
\text { Inv. }\end{array}$ \\
\hline 2005 & 11 & 0 & 0 & 9830 & 176 & 15.4 & 0.25 & 844 & 34.5 & 59.1 & 2.72 & 9830 \\
\hline 2004 & 11 & 0.1 & 0.2 & 9900 & 193 & 14.1 & 0.27 & 827 & 34.4 & 57.0 & 2.63 & 8610 \\
\hline 2003 & 11 & 0 & 0 & 9430 & 133 & 15.5 & 0.24 & 838 & 35.7 & 59.7 & 2.83 & 8180 \\
\hline 2002 & 11 & 0 & 0 & 10600 & 19.3 & 8.17 & 0.14 & 825 & 43.3 & 23.9 & 1.37 & 10400 \\
\hline 2001 & 11 & 0.033 & 0.07 & 10000 & 211 & 12.3 & 0.26 & 841 & 40.4 & 50.4 & 2.93 & 7790 \\
\hline 2000 & 11 & 0 & 0 & 10100 & 96 & 9.2 & 0.16 & 852 & 48.1 & 34.9 & 2.19 & 9310 \\
\hline 1999 & 11 & 0.533 & 0.7 & 10200 & 182 & 9.8 & 0.28 & 883 & 54.6 & 40.7 & 2.66 & 8750 \\
\hline
\end{tabular}


Table 19 Simulation Results for Guideline 12 for Yahoga 1999 - 2005

\begin{tabular}{|c|c|c|c|c|c|c|c|c|c|c|c|c|}
\hline Year & Policy & $\begin{array}{l}\text { Ave. \# of } \\
\text { Stockouts }\end{array}$ & $\frac{ \pm}{\mathrm{Cl}}$ & $\begin{array}{l}\text { Ave. } \\
\text { Inv. } \\
\text { Level }\end{array}$ & $\frac{ \pm}{\mathrm{Cl}}$ & $\begin{array}{c}\text { Ave. \# of } \\
\text { Orders } \\
\text { Received }\end{array}$ & $\begin{array}{l} \pm \\
\mathrm{Cl}\end{array}$ & $\begin{array}{l}\text { Ave. Amt. } \\
\text { Ordered }\end{array}$ & $\frac{ \pm}{\mathrm{Cl}}$ & $\begin{array}{l}\text { Ave. \# of } \\
\text { Order Rec. }\end{array}$ & $\begin{array}{l} \pm \\
\mathrm{Cl}\end{array}$ & $\begin{array}{l}\text { Ave. } \\
\text { Min. } \\
\text { Inv. }\end{array}$ \\
\hline 2005 & 12 & 0 & 0 & 10700 & 133 & 14.7 & 0.33 & 837 & 32.7 & 56.4 & 2.29 & 9600 \\
\hline 2004 & 12 & 0.133 & 0.27 & 10400 & 190 & 13.5 & 0.27 & 831 & 37.2 & 53.5 & 2.47 & 9210 \\
\hline 2003 & 12 & 0 & 0 & 10100 & 96.6 & 15.7 & 0.19 & 833 & 31.9 & 56.8 & 2.31 & 9360 \\
\hline 2002 & 12 & 0 & 0 & 11400 & 17.8 & 7.67 & 0.18 & 821 & 48.2 & 20.7 & 1.17 & 11200 \\
\hline 2001 & 12 & 0 & 0 & 10400 & 205 & 12.4 & 0.30 & 831 & 37.8 & 47.7 & 2.59 & 8490 \\
\hline 2000 & 12 & 0 & 0 & 11100 & 91.8 & 8.3 & 0.17 & 860 & 50.5 & 31.5 & 1.98 & 10500 \\
\hline 1999 & 12 & 1.1 & 0.77 & 11200 & 205 & 9.1 & 0.21 & 864 & 55.7 & 38.7 & 2.52 & 9570 \\
\hline
\end{tabular}

From the simulation we found that the higher stockout number for guideline 12 was caused by a large average stockout in 1999. Outside of the results of 1999 for all guidelines we found that the average number of stockouts for guideline 11 and 12 is the lowest and equal for the two guidelines. The tie breaker would thus go to guideline 12 because of lower average orders placed and received. This guideline also maximized the average minimum inventory, which is important because of the unpredictable nature of the weather and supply.

The simulated inventory levels in Figure 15 and Figure 16 are the daily averages from 30 replications of the simulation. Figure 15 shows the simulated inventory levels using guideline 1 for Yahoga during November 2004 March 2005 and the actual inventory level for Yahoga during this period. Guideline 1 implements the $(R, S)$-inventory guideline using the actual beginning inventories provided by DOT as the inventory level on November $1^{\text {st }}$.

Figure 16 shows the inventory levels for November 2004 - March 2005 for Yahoga utilizing the best overall guideline for all counties, guideline 12. Guideline 12 starts the season on November $1^{\text {st }}$ with the stock target level for January and the $(R, S)$ guideline for December and January begins 7 days early in the preceding month with no changes to the $(R, S)$ parameters in February and March. Figure 17 shows the actual received amounts provided by DOT between November $1^{\text {st }}$ and March $31^{\text {st }}$. Figure 18 show one replication of simulated received amounts between November $1^{\text {st }}$ and March $31^{\text {st }}$ using the proposed $(R, S)$ inventory guideline.

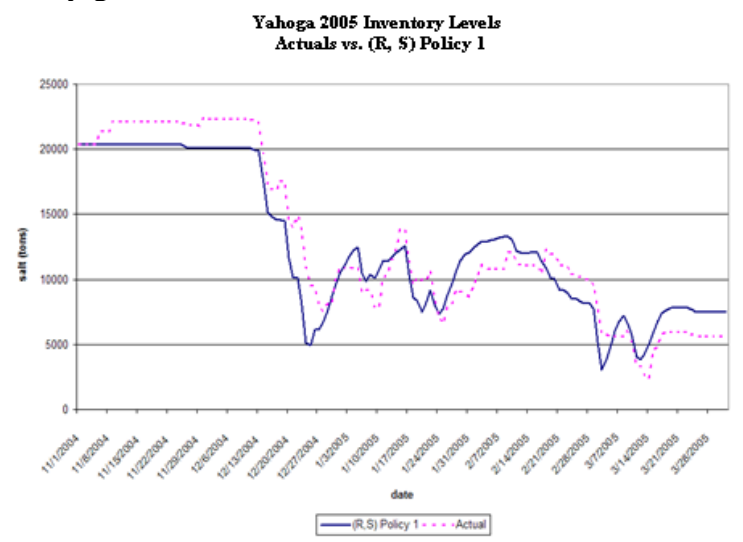

Figure 15 Yahoga Actual Inventories vs. Inventories Applying $(R$, S) Guideline 1 for November 2004 - March 2005

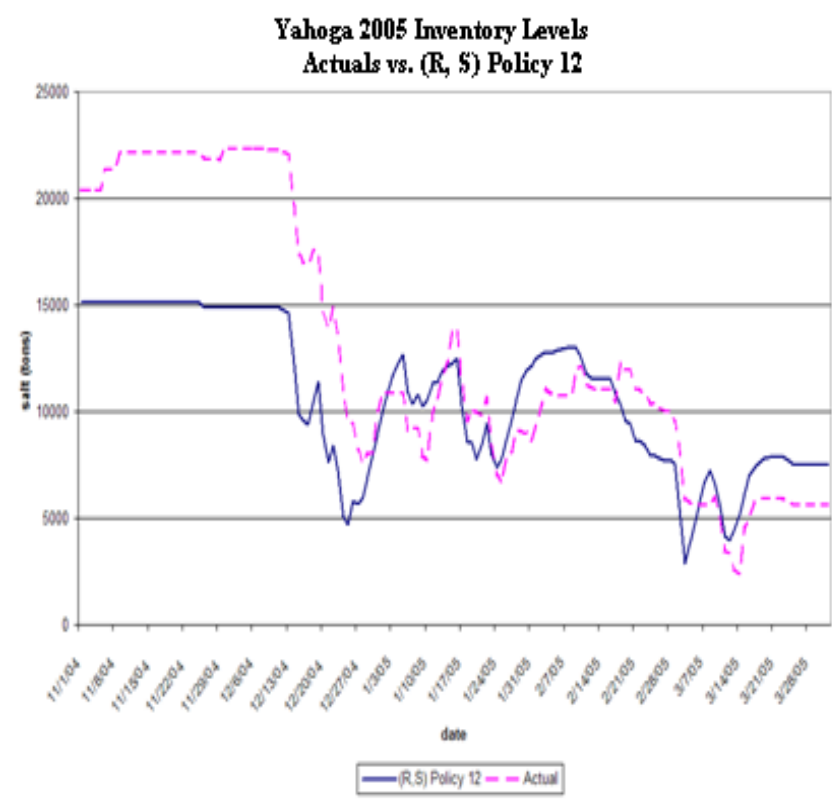

Figure 16 Yahoga Actual Inventories vs. Inventories Applying $(R$, S) Guideline 12 for November 2004 - March 2005

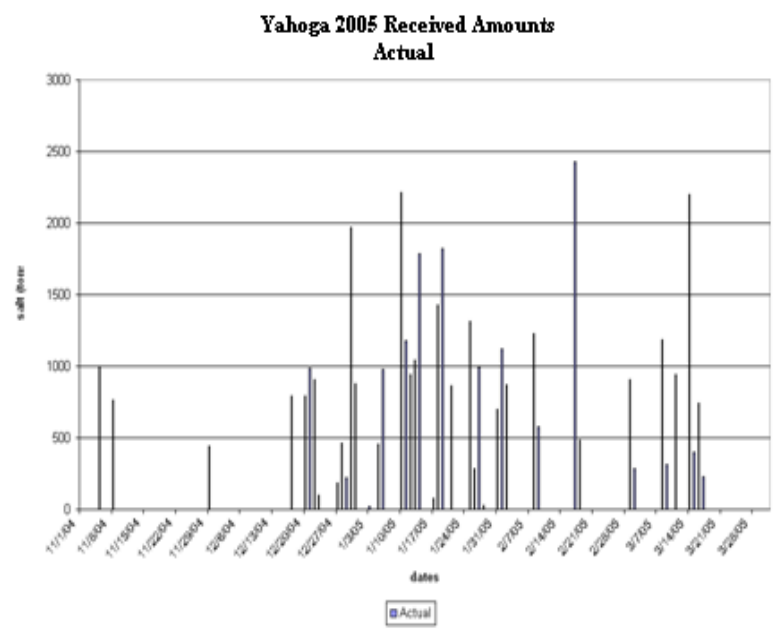

Figure 17 Yahoga Actual Received Amounts from November 2004 - March 2005 


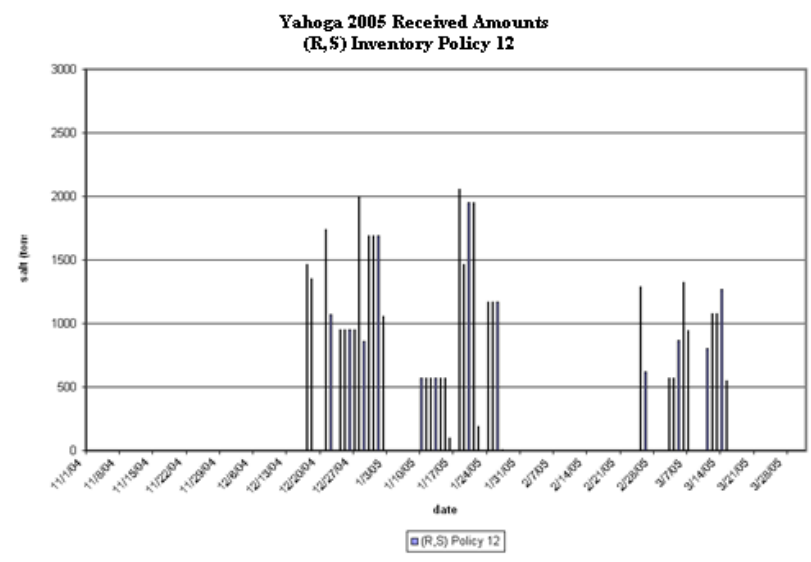

Figure 18 Yahoga $(R, S)$ Guideline Received Amounts from November 2004 - March 2005

\section{MANAGERIAL IMPLICATION AND CONCLUSION}

The $(R, S)$-inventory guideline allows the inventory manager to make systematic decisions about whether to order and how to much order. Orders in this inventory guideline are made weekly based on the reorder point, $R$. The order amount is determined by the target level and current inventory level. In this research, we related these guidelines to the actual historical usage of salt in the State counties. We compared these results to a very conservative policy from the DOT maintenance administration manual based on the historical 10-day maximum usage. Based on the detailed county-by-county comparison with the 10 day maximum usage guideline (not included in the paper for brevity), the conclusions of this analysis and comparison were: i) For four counties in the state, the 10 day maximum usage is significantly larger than the suggested inventory targets: It may be possible to reduce the inventories in these counties without a negative service level impact, ii) For thirteen counties, the 10 day maximum usage is moderately larger than the suggested inventory targets: For these thirteen counties, our analysis indicates considering a moderate decrease in inventory will not negatively the level of service, iii) In both cases, the decision to decrease inventory levels should be balanced with any additional practical issues not considered explicitly in this analysis, iv) For five counties, the 10 day maximum usage is moderately smaller than the suggested inventory targets: For these five counties our analysis indicates that considering a moderate increase in the inventory levels is necessary to maintain an adequate level of service, v) For three counties, the 10 day maximum usage is significantly smaller than the suggested inventory targets: It is likely that increasing the inventories in these counties can improve the level of service. It is worth noting that all three of these counties have among the highest overall usage in the state. If deliveries from the vendors to these counties are more reliable than to other counties because of the regularity of delivery and the volume of orders, then the 10 day max may be acceptable as an inventory target.
In all of the other county studies, the difference between our suggested inventory target and the 10 day maximum usage was relatively small. We recommend that no change be made in the inventory guideline for these counties.

The suggested inventory targets were also compared to the reported storage capacities in each county as of September 2007. Based on this comparison we identified counties that had a significant storage deficiency (two counties were identified). Changes in storage capacity since this time have increased the storage capacity in the two counties identified. We also identified counties that had a marginally acceptable storage capacity, both on an absolute basis as well as a percentage basis (three counties were identified). This analysis will support focusing on these counties as salt usage increases. Overall, our methodology of comparing capacities to order targets has been adopted as one of the standard features of DOT's monthly Salt Usage reporting.

From a managerial perspective, the following are the important contributions of this research:

- A regression model methodology to predict the usage of salt in a county based on the weather reported via daily NOAA reports for the major city in that county.

- A methodology for using those models, together with a lane-mile adjustment and a weather zone assignment, to make salt usage predictions for counties that do not contain a major city.

- A framework for using the salt usage prediction from these models, or raw usage data from the counties, to develop $(R, S)$ inventory control guidelines that satisfy a given level of service and minimize the stock required to achieve that level of service.

- $\quad$ Specific analysis for each of the counties that develops the $(R, S)$ parameters for each county, for each month of the winter season.

- A simulation study to help guide the implementation of the $(R, S)$ guidelines. The results of this study provide guidelines for implementing some of the current practices in inventory ordering together with the suggested $(R, S)$ guidelines. This includes how to transition the guidelines from month to month through the winter season and still achieve the designed levels of service.

- A comparison via simulation of the pattern of orders that are generated using the suggested $(R, S)$ guidelines, vs the actual pattern of orders. This comparison would be useful to share with suppliers to help understand how the implementation of the new guidelines would affect the orders they receive.

In practice it is difficult to track inventory when the supply is not carefully monitored. A topic of future study is how inaccuracy in inventory tracking affects the inventory guideline.

Future work that builds on the results of this research also includes the consideration of tactics for an increasingly collaborative relationship with suppliers through the appropriate sharing of information and risks. Through this enhanced collaborative approach, the suppliers will have the 
incentive and the tools to provide the highest levels of service to the State.

\section{REFERENCES}

Arnsler, D.E., Sr, "Inventory Management of Solid Ice Control Chemicals (Salt)", Salt \& Highway Deicing Newsletter, Salt Institute, Spring 2004

Chaturvedi, A., and Martinez-de-Albéniz V. (2011). Optimal Procurement Design in the Presence of Supply Risk. Manufacturing \& Service Operations Management, 13(2), pp. 227-243.

Chiang, W.C., and Russell, R.A. (2004). Integrating Purchasing and Routing in a Propane Gas Supply Chain. European Journal of Operational Research, 154(3), pp. 710-729.

Ciarallo, F.W., Akella, R., and Morton, T.E. (1994). A Periodic Review Production Planning Model with Uncertain Capacity and Uncertain Demand - Optimality of Extended Myopic Policies. Management Science, 40(3), pp. 320-332.

Ciarallo, F.W., Brown, N., and Niranjan, S. (2009). Enhancement of Winter Maintenance Material Ordering and Inventory. The Ohio Department of Transportation Office of Research \& Development. Technical Report FHWA/OH-2009/1.

Gao, Y., Wen, M., and Ding, S. (2013). $(s, S)$ Policy for Uncertain Single Period Inventory Problem. International Journal of Uncertainty, Fuzziness and Knowledge-Based Systems, 21(06), pp. 945-953.

Gumus, M., Ray, S., and Gurnani, H. (2012). Supply Side Story: Risks, Guarantees, Competition and Information Asymmetry. Management Science, 58(9), pp. 1694-1714.

Hajiaghaei-Keshteli, M., Sajadifar, S.M., and Haji, R. (2010). Determination of the Economical Policy of a Three-Echelon Inventory System with $(R, Q)$ Ordering Policy and Information Sharing. The International Journal of Advanced Manufacturing Technology, 55(5-8), pp. 831-841.

Hanbali, R.M, and Kuemmel, D.A. (1992). Traffic Volume Reductions Due to Winter Storm Conditions. $3^{\text {rd }}$ International Symposium on Snow Removal and Ice Control Technology, Minneapolis, Minnesota, pp. 159-164.

Hayashai, A., Ishii, N., and Matsui, M. (2009). A Theory and Tools for Collaborative Demand-to-Supply Management in the SCM Age. Operations and Supply Chain Management, 2(2), pp. 111-124.

He, Y.. and Zhao, X. (2012). Coordination in Multi-Echelon Supply Chain under Supply and Demand Uncertainty. International Journal of Production Economics, 139(1), pp. 106-115.

Iida, T. (2015). Benefits of Leadtime Information and of its Combination with Demand Forecast Information. International Journal of Production Economics, 163(1), pp. 146-156.

Katehakis, M.N., and Smit, L.C. (2012). On Computing Optimal $(Q, r)$ Replenishment Policies under Quantity Discounts. Annals of Operations Research, 200(1), pp. 279-298.
Kelton, D.W., Sadowski, R.R., and Sturrock, D.T. (2004). Simulation with Arena ( $3^{\text {rd }} \mathrm{ed}$.), McGraw-Hill Education.

Maintenance Administration Manual (2005). Ohio Department of Transportation, Internal Document.

Keramydas, C., Xanthopolous, A., and Aidonis, D. (2011). A Decision-Making Framework for the Optimal Selection of Suppliers, Operations and Supply Chain Management 4(2/3), pp. 68-77.

Knapp, K.K., Smithson, L.D., and Khattak, A.J. (2000). The Mobility and Safety Impacts of Winter Storm Events in a Freeway Environment. Mid-Continent Transportation Symposium Proceedings, pp. 67-71.

Lee, J.Y., and Behnezhad, A. (2015). Incremental Quantity Discounts in a Periodic-Review Stochastic Inventory Model with a General Demand Distribution. International Journal of Mathematics in Operational Research, 7(2), pp. 178-193.

Ma, L., Chai, Y., Zhang, Y., and Zheng, L. (2014). Modeling and Analysis of the Multi-echelon Inventory in Supply Chain. Journal of Computational Information Systems, 10(15), pp. 6363-6371.

McCullouch, B., Belter, D., Konieczny, K., and McClellan, T. (2004). Indiana Weather Severity Index. In Proceedings of $6^{\text {th }}$ International Symposium on Snow Removal and Ice Control Technologie, Spokane. June 7-9, pp. 167-178.

McHugh, M., Humphreys, P., and McIvor, R. (2003). BuyerSupplier Relationships and Organization Health. Journal of Supply Chain Management, 39(1), pp. 15-25.

Montgomery, D.C., and Runger, G.C. (2003). Applied Statistics and Probability for Engineers ( $3^{\text {rd }}$ ed.), John Wiley and Sons Inc.

Nahmias, S. (2005). Production and Operations Analysis ( $5^{\text {th }}$ ed.), McGraw-Hill Irwin.

"National Climatic Data Center" (Online). National Oceanic and Atmospheric Administration (NOAA) Web Site. Accessed at http://www.ncdc.noaa.gov/oa/ncdc.html on September 5, 2006.

Parlar, M., Wang, Y., Gerchak, Y. (1995). A Periodic Review Inventory Model with Markovian Supply Availability. International Journal of Production Economics, 42(2), pp. 131-136.

Qin, Z., and Kar, S. (2013). Single-period Inventory Problem under Uncertain Environment. Applied Mathematics and Computation, 219(18), pp. 9630-9638.

Roelants, T., and Muyldermans L. (2002). Salt Stock Management Based on an $(R, S)$-Inventory Policy. Proceedings of XIth International Winter Road Congress, PIARC World Road Association, Sapporo, Japan, Jan. 28-31.

Tempelmeier, H. (2013). A multi-level inventory system with a make-to-order supplier. International Journal of Production Research, 51(23/24), pp. 6880-6890.

Tempelmeier, H., and Fischer L. (2010). Approximation of the Probability Distribution of the Customer Waiting Time under an $(r, s, q)$ Inventory Policy in Discrete Time. International Journal of Production Research, 48(21), pp. 6275-6291.

"Winter Maintenance Material Ordering \& Inventory". Ohio Department of Transportation, Internal CD-ROM, 2006.

Frank W. Ciarallo, $\mathbf{P h D}$, is an Associate Professor in the College of Engineering \& Computer Science at Wright State University in Dayton, Ohio. His research interests include: control and management of supply chain systems, interaction of risk and competition in game theoretic models of inventory systems, supply uncertainty and risk in inventory models, multiobjectivization as a technique for solving difficult single-objective optimization problems via evolutionary algorithms, software and conceptual modeling tools for more effective simulation modeling and agent-based modeling of systems. 
Suman Niranjan (Ph.D., Engineering, Industrial and Human Systems) is an Associate Professor of Operations Management at College of Business Administration-Savannah State University. His research interests lie in inventory control and optimization, supply chain optimization, applied discrete-event simulation, applied Monti Carlo simulation, reverse logistics, multi-variate statistical analysis, cross-cultural research, and entrepreneurship. His research has appeared in journals that include Issues in Decision Sciences, International Journal of Advanced Operations Management, International Journal of Business Performance and Supply Chain Modelling, Journal of Leadership and Organizational Studies, Accounting \& Taxation, and Journal of Managerial Issues.

Nick Brown (M.S., Human Factors Engineering) is a Senior Independent Consultant specializing in the design, coordination, and analysis of business processes through the use of modeling and simulation. His research interests lie in the development of data-driven simulation models that are built as a complete decision support tool allowing for re-usability and ease of use to the end user. This research was presented at the 2010 Winter Simulation Conference in Baltimore, MD. Past projects include working on large scale military weapon systems, multi-national retail chain operations, university hospital networks, and large scale integrated supply chains. 